\title{
A Systematic Review of Consumer Perceptions of Smart Packaging Technologies for Food
}

\author{
Erin Young, Miranda Mirosa* and Phil Bremer \\ Department of Food Science, University of Otago, Dunedin, New Zealand
}

Smart packaging, an emerging technology in the food packaging industry incorporates both active and intelligent technologies. Consumer demand for natural products and increasingly extended and diverse supply chains required to feed the growing global population, mean that traditional packaging is becoming less capable of meeting the functional demands placed on it. To help ensure the commercial success of proposed smart packaging technologies a thorough understanding of consumers attitudes toward them is required. Understanding the cultural, social and cognitive factors that affect acceptance will help "fine tune" smart packaging development to best meet consumer preferences and needs and ensure that communication about the technologies effectively

OPEN ACCESS

Edited by:

Sara Limbo,

University of Milan, Italy

Reviewed by:

Miguel Cerqueira,

International Iberian Nanotechnology

Laboratory (INL), Portugal

Carlos Eduardo Orrego,

National University of Colombia

Manizales, Colombia

*Correspondence:

Miranda Mirosa

miranda.mirosa@otago.ac.nz

Specialty section:

This article was submitted to

Sustainable Food Processing,

a section of the journal

Frontiers in Sustainable Food Systems

Received: 20 December 2019

Accepted: 17 April 2020

Published: 13 May 2020

Citation:

Young $E$, Mirosa $M$ and Bremer $P$ (2020) A Systematic Review of Consumer Perceptions of Smart

Packaging Technologies for Food.

Front. Sustain. Food Syst. 4:63.

doi: 10.3389/fsufs.2020.00063 addresses consumer concerns and educates them on the benefits. This systematic review of 28 peer reviewed journal articles summarizes the current knowledge on consumer acceptance or rejection of active and intelligent packaging, and the behavioral forces behind those attitudes. Articles containing primary data and published in the English language over the last 10 years reporting consumer responses to active and/or intelligent packaging technologies in general or to more specific technologies that achieved the functional goals of active or intelligent packaging were obtained and analyzed for themes in the qualitative data analysis software NVivo. Themes were organized into groups as to whether they identified control variables, moderating variables, barriers or motivations to purchase and the benefits of the technology. To develop a conceptual framework for understanding consumer preferences for smart packaging, the identified themes were integrated with several consumer behavior models including the theory of planned behavior and an attitude model. Consumer perceptions of smart packaging is a poorly covered research area with most research being clustered in Europe and a smaller cluster in the Americas so there were significant opportunities to build on the body of knowledge.

Keywords: active packaging, intelligent packaging, smart packaging, consumer acceptance, consumer perception, systematic review

\section{INTRODUCTION}

Consumers don't purchase packaging; they purchase food products that happen to have packaging built into the product offering. Therefore, when researching the impact food packaging has on consumer food choice, it is important to center the discussion on how packaging changes the value equation for the food products themselves. Köster (2009) states that packaging is an extrinsic 
product characteristic in food choice, one of six key determinants involved. It can be argued however that packaging interacts with some, if not all of the other factors given it is a fundamental part of the food product at the point of purchase, e.g., intrinsic characteristic through different levels of protection or psychological factors where novel packaging interacts with a consumer's food neophobia.

But beyond influencing food choice, packaging is incorporated into a food product as a tool to provide functional benefits to the packaged food product. The functions of packaging are most commonly split into four functions (Robertson, 2013) of containment, protection, communication and convenience.

Conventionally food packaging has been passive, with packaging materials being adjusted to meet the requirements of the product, consumer, and supply chain stakeholders. More recent developments also utilize the packaging headspace rather than just the materials to enhance the protective function (e.g., vacuum packing and modified atmosphere packing), but these are still passive once the packing process is complete. However, the industry is driven by market changes and as such conventional methods may no longer be sufficient. The driving forces for change fit broadly into several categories encompassing changes to consumer lifestyle, and increasing food safety, biosecurity, and environmental concerns (Yam and Lee, 2012). Consumers want safe and convenient food, that they can perceive as being "natural" (i.e., less processed), and packed in recyclable or reusable materials. Smart packaging, by taking packaging from a passive to active state is better able to meet these potentially conflicting demands than traditional packaging. Smart packaging is a collective term used to group some emerging packaging technologies (in the food packaging industry) that interact with the consumer and/or the product in an enhanced way, namely the innovative packaging technologies referred to as "active packaging" and "intelligent packaging".

These terms, "active packaging" and "intelligent packaging" relate to a general functional goal over and above passive "dumb" packaging, and as such utilize a range of technologies to achieve the functional goal. The purpose of adding active packaging functionality to a food product/packaging system is to improve the protective functional value e.g., antimicrobial materials or oxygen absorbers (Robertson, 2013). The purpose of adding intelligent packaging functionality to a food product/packaging system is to improve its epistemic value (providing additional information about the product) e.g., time temperature indicators or ripeness indication (Robertson, 2013).

One significant area of technological overlap with active and intelligent packaging is that of nanotechnology applied to the food packaging industry (Figure 1). Nanotechnology refers to structures that have dimensions in the range of one billionth of a meter (Poole and Owens, 2003). Nanotechnology is a platform technology and can be utilized in packaging to achieve the aims of smart packaging but has potential to pose health risks (Alfadul and Elneshwy, 2010). It must also be noted that the use of nanotechnology in food processing or packaging has the potential to cause significant consumer concerns (Siegrist et al., 2007).

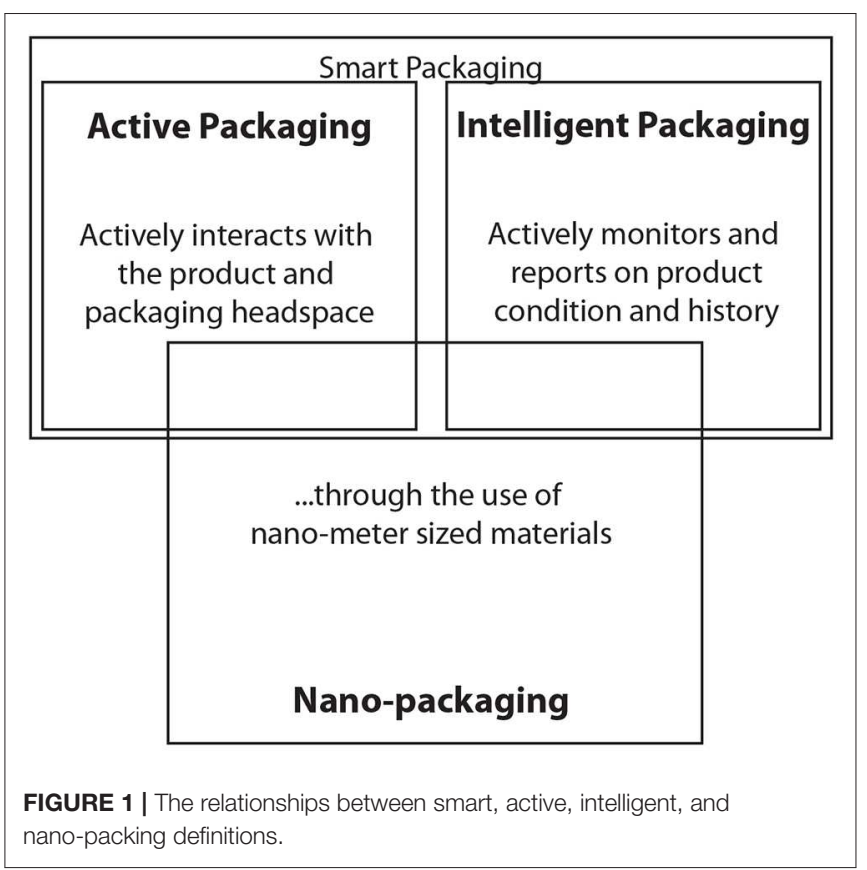

For commercial success food products utilizing innovative active or intelligent packaging technologies must be accepted by consumers. Based on the challenge of introducing genetically modified organisms (GMO), it is evident that consumer acceptance of novel technologies cannot be assumed. While consumers consider cost, safety and quality in their purchasing decisions, they are also emotional creatures and credence factors such as production practices and ethics are playing an increasingly important role in such decisions (Dagevos and van Ophem, 2013). Therefore, the aim of this systematic review was to collate and review papers dealing with consumer perceptions of active and intelligent packaging technologies in general, as well as consumer perceptions of the specific technologies (including nanotechnologies) that achieve the goals of active and intelligent packaging. Articles on nanopackaging where smart packaging functional goals are explicitly stated to participants were including owing to their significant overlap with smart packaging. This approach enabled the researchers to determine if consumer perceptions of the use of nanotechnology in food packaging are similar or different to other consumer perceptions on smart packaging. The purpose of reviewing the aggregate knowledge was to derive a conceptual model to help to understand consumer motives and barriers to the purchase of food products that utilize smart packaging technologies, as well as to determine the moderating, and control variables that influence their behavior. Such a model will enable technology developers to design products incorporating smart packaging technologies, with consumer preferences and needs in mind and facilitate the communication of information to consumers to enhance their acceptance of the technology. 


\section{MATERIALS AND METHODS}

The aim of the study can be broken down into 4 objectives:

1. Understand the research methods, theories, geographic scope, moderating, independent, and dependent variables utilized in the selected studies.

TABLE 1 | Search terms used for system review.

\begin{tabular}{|c|c|c|c|c|}
\hline $\begin{array}{l}\text { Term } 1 \\
\text { (title-abstract- } \\
\text { keywords) } \\
\text { OR }\end{array}$ & And & $\begin{array}{l}\text { Term } 2 \text { (title- } \\
\text { abstract-keywords) } \\
\text { OR }\end{array}$ & And & $\begin{array}{l}\text { Term } 3 \\
\text { (title-abstract- } \\
\text { keywords) } \\
\text { OR }\end{array}$ \\
\hline Consum* & & Smart & & Packaging \\
\hline \multirow[t]{34}{*}{ Food choice } & & Novel & & \\
\hline & & Active & & \\
\hline & & Intelligent & & \\
\hline & & Oxygen absor & & \\
\hline & & O2 absor & & \\
\hline & & Oxygen scaveng* & & \\
\hline & & O2 scaveng ${ }^{*}$ & & \\
\hline & & Oxygen emit* & & \\
\hline & & $\mathrm{O} 2$ emit $^{\star}$ & & \\
\hline & & Carbon dioxide absor ${ }^{*}$ & & \\
\hline & & CO2 absor ${ }^{*}$ & & \\
\hline & & Carbon dioxide emit* & & \\
\hline & & $\mathrm{CO} 2$ emit* $^{\star}$ & & \\
\hline & & Ethylene absor* & & \\
\hline & & Ethylene emit* & & \\
\hline & & Ethanol emit ${ }^{\star}$ & & \\
\hline & & Moisture absor* & & \\
\hline & & Antioxidant & & \\
\hline & & Antimicrobial & & \\
\hline & & $\mathrm{Nano}^{*}$ & & \\
\hline & & Flavor absor* & & \\
\hline & & Odor absor* & & \\
\hline & & Flavor release & & \\
\hline & & Odor release & & \\
\hline & & Gas permeability & & \\
\hline & & Quality indicator & & \\
\hline & & Fresh $^{\star}$ indicator & & \\
\hline & & $\begin{array}{l}\text { Time temperature } \\
\text { indicator }\end{array}$ & & \\
\hline & & $\begin{array}{l}\text { Radio frequency } \\
\text { identification }\end{array}$ & & \\
\hline & & Quality sensor & & \\
\hline & & Fresh* sensor & & \\
\hline & & $\begin{array}{l}\text { Gas concentration } \\
\text { sensor }\end{array}$ & & \\
\hline & & $\begin{array}{l}\text { Gas concentration } \\
\text { indicator }\end{array}$ & & \\
\hline & & Biosensor & & \\
\hline
\end{tabular}

*was utilized as the wildcard to collect and retrieve more complex variations of the search terms shown.
2. Confirm the motives and barriers that most significantly impact on purchase intent.

3. Identify and understand the impact of the independent variables.

4. Clarify the association between motives, barriers, and purchase intent for food packaging with active or intelligent packaging.

A systematic literature search using Scopus and Web of Science databases was conducted in January 2019. The methodological process followed a formal systematic review protocol in line with the Prisma protocols (Moher et al., 2009). The search terms (Table 1) covered generic terms for various types of smart packaging as well as the specific packaging technologies that achieve the functional objectives of smart packaging. The searches in both databases were limited to the English language, and date range from 2009 to 2019.

The recovered articles titles and abstracts were screened against the inclusion and exclusion criteria (Table 2), the results from the two databases [Scopus $(n=3932)$ and Web of Science $(n=5063)]$ were then combined, duplicates removed, and the full text of each article was then assessed for eligibility into the final review.

Additional eligible articles were obtained via a citation and reference check of all eligible articles, and subsequently screened and confirmed as being eligible through the same inclusion and exclusion criteria. A second search was conducted and screened in February 2020 to ensure all recent publications were captured within the review. The final number of studies incorporated into the final systematic review was 28 (Figure 2).

Eligible articles (Supplementary Table 1) were then analyzed utilizing reflexive thematic analysis techniques (Braun and

TABLE 2 | Inclusion and exclusion criteria for screening and eligibility.

\begin{tabular}{ll}
\hline Inclusion criteria & Exclusion criteria \\
\hline $\begin{array}{ll}\text { Quantitative or qualitative primary } \\
\text { empirical data studies }\end{array}$ & $\begin{array}{l}\text { Review articles, opinion papers and } \\
\text { outlooks, conference papers, and } \\
\text { abstracts }\end{array}$
\end{tabular}

Full-text articles published in peer-review journals in the English

Not related to consumer behavior or language from 2009 onwards.

Articles on consumer perceptions or Not related to food or beverages acceptance of active packaging applications for food products

Articles on consumer perceptions or acceptance of intelligent packaging Articles focusing on the technology itself, sensory results only or life cycle analysis

Articles on consumer perceptions or acceptance of nano-food or nano-packaging technologies where an application to achieve active or intelligent food packaging functionality is clearly stated to research participants
Articles focusing on consumer responses to packaging labeling or packaging attributes that are not active, intelligent or smart technologies nano-food/nano-packaging 


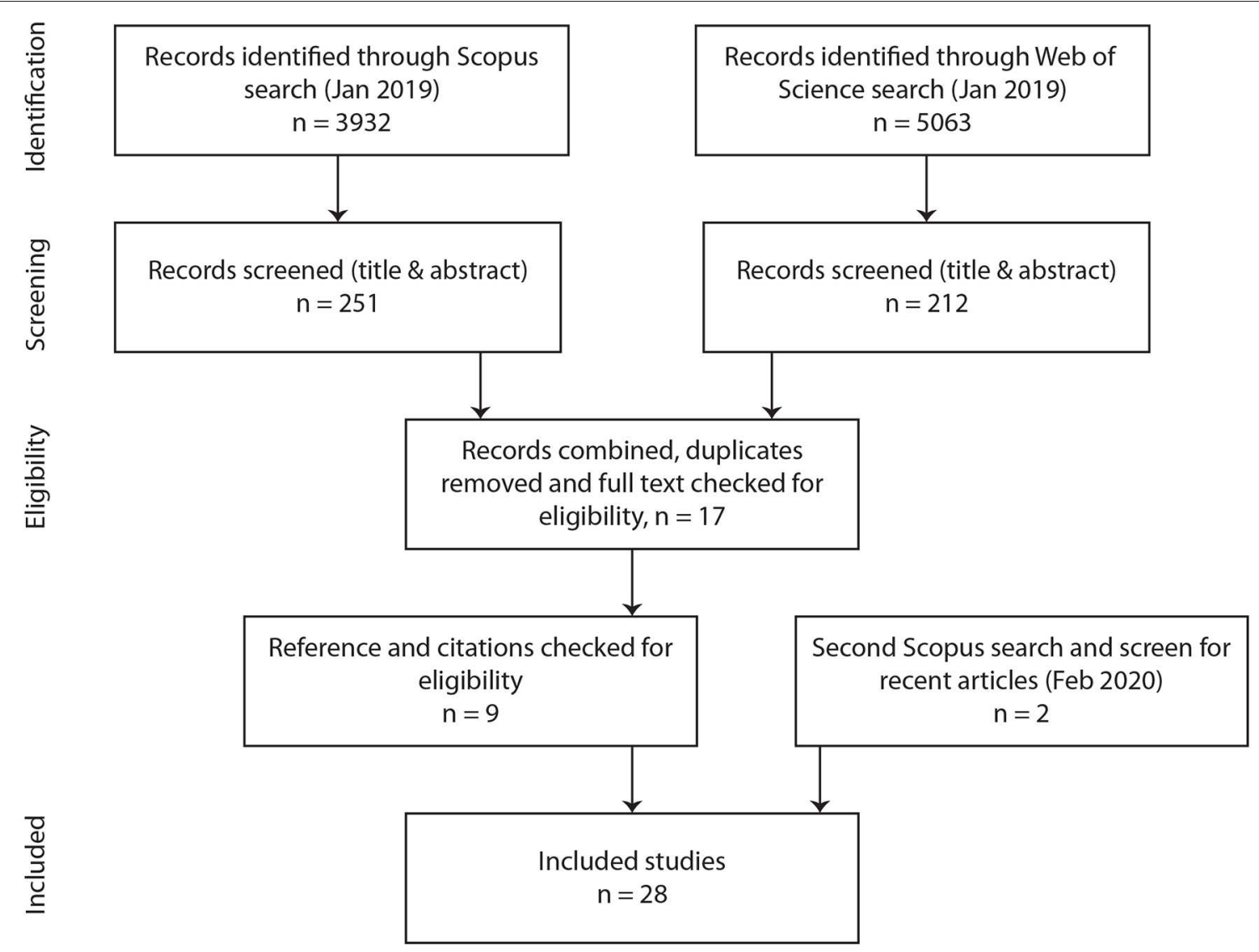

FIGURE 2 | Identification and screening flow diagram.

Clarke, 2006, 2019) in NVivo 12.5. For the purpose of building a conceptual consumer behavior model, themes were generated from the codes applied and discussed with the purpose of understanding the motives, barriers, moderators and control variables influencing consumer acceptance, preference and willingness to buy/pay for food products with smart packaging solutions applied.

\section{RESULTS}

\section{Technological Focus of the Studies}

Of the 28 included studies, 13 were focused on nanopackaging, and had examples which incorporated active and/or intelligent packaging functionality. Eight studies were focused on general active and intelligent packaging, with 6 of these papers coming from the same research team. Seven studies focused on eliciting consumer responses to specific smart packaging technologies and/or applications of various smart packaging technologies to specific food products or food groups (Figure 3).

\section{Geographic Scope}

Studies were clustered predominantly in Europe, with a small secondary cluster in North America, one study in North Africa and one study in South America. There were no eligible studies from Asia, the Middle East, or Oceania (Figure 4), although one study did look at supply chain feedback from Japan but the consumer insights were presumed to be only from Finland (Lindqvist et al., 2012).

One of the studies (Van Wezemael et al., 2011) looking at specific food groups encompassed 5 European countries, while another (Pennanen et al., 2015) looking at specific technologies (TTIs) encompassed 4 European countries. All other studies used had data from a single country.

\section{Research Methods}

One study used both qualitative (focus group) and quantitative (survey) methodologies (Pennanen et al., 2015), four studies were qualitative (Greehy et al., 2011; Lindqvist et al., 2012; Gupta et al., 2015; Daoud and Trigui, 2019), with the remaining 23 studies being quantitative (Figure 5). One study (Katare et al., 2016) used both experimental auctions and an eye tracking study.

\section{Consumer Behavior Theories}

Nearly half of the articles did not cite a behavior theory as being part of their analysis (Figure 6). An article by Siegrist et al. (2007) proposed a model that takes a psychological approach toward a better understanding of the acceptance of 


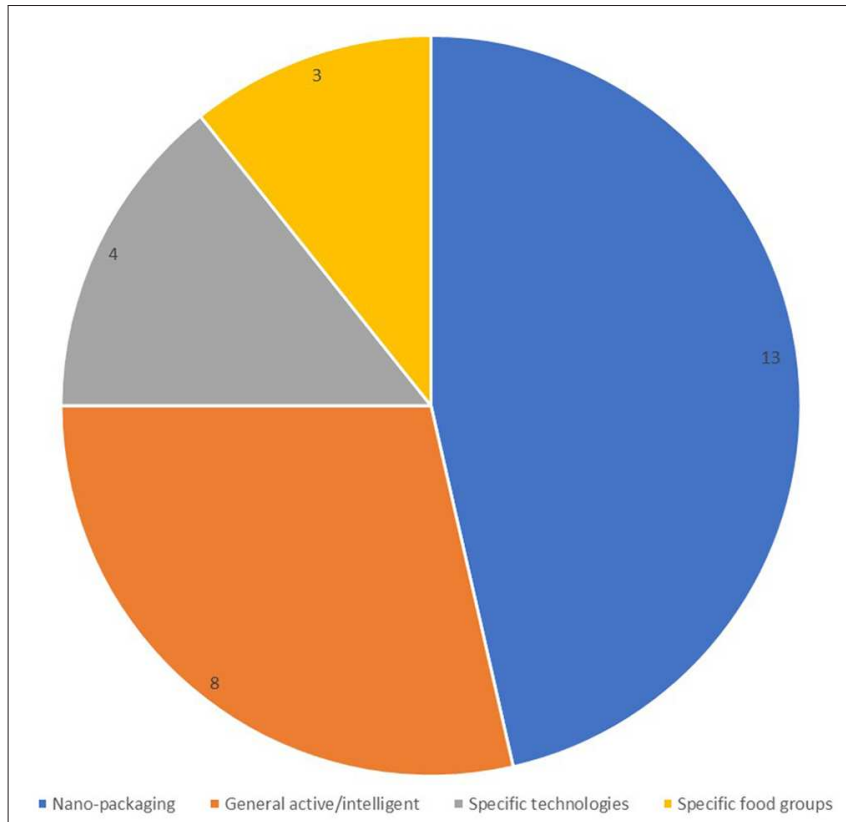

FIGURE 3 | Technological focus of the studies.

food nanotechnology (including nanotechnology enhanced food packaging), which incorporated trust, affect, and perceptions of risk, and benefits in determining willingness to purchase. Five of the articles attempted to duplicate their work in other countries, while the Siegrist model was cited in most of the studies on nanotechnology.

Another cluster of articles [from the same research group, (Loučanová et al., 2016, 2017, 2018, 2019a,b)] use the Kano model to link prioritization of packaging functions with preference for smart packaging technologies. Remaining articles derived a value driven model (Lindqvist et al., 2012), investigated the relationship between food neophobia and acceptance of packaging nanotechnology (Matin et al., 2012), one used the theory of planned behavior to compare traceable packaging with standard packaging for meat products (Spence et al., 2018) and two utilized the random utility theory (Erdem, 2015; Zhou and $\mathrm{Hu}, 2018)$.

\section{Dependent Variables}

The dependent variables cited in the studies were acceptance of, preferences for, attitudes toward and willingness to pay for food products enhanced with active, and intelligent packaging. Some studies also looked at familiarity with active, intelligent, and nanotechnologies.

The general consensus from the studies was that consumer attitudes ranged from indifference to cautious acceptance and willingness to pay for smart packaging technologies. Pennanen et al. (2015, p. 319) stated some acceptance: "European consumers are interested and, at least to some extent, willing to adopt intelligent food packaging with incorporated TTI indicators," whereas Erdem (2015, p. 272) suggested indifference: "the presence of nanosensors in packaging does not seem to have a significant effect on consumers' likelihood of purchase when the level of food risk decreases." Rejection tended to be isolated to subgroups within study populations rather than the full population of the study. For example, Van Wezemael et al. (2011, p. 48) found this where a particular group of consumers considered that "changing packaging characteristics to enhance beef safety was not acceptable," whereas another cluster of participants had "high acceptance levels on all packaging technologies, and especially for nonfamiliar packaging technologies."

\section{Moderating Variables}

Moderating variables discussed in the included articles tended to fall into three groups; (1) perceptions of value; (2) perceptions of barriers; (3) a variety of existing beliefs, mind-set, familiarity and knowledge, which appear to directly acceptance or influence both the perception of the motives and barriers, which in turn then influenced acceptance.

\section{Perceptions of Value of Using Active and Intelligent Packaging}

Consumers perceived a number of benefits associated with active and intelligent packaging, including functional benefits such as improving food safety and quality by minimizing deteriorative food reactions. The primary purpose of intelligent packaging is to provide additional information about the quality and history of the food product (Robertson, 2013), thereby providing additional epistemic value as noted by a significant proportion of participants in the studies.

\section{Perceptions of Barriers to Using Active and Intelligent Packaging}

Barriers to purchasing products enhanced with active and intelligent packaging technologies were more varied, and included concerns about the additional cost for food items incorporating active or intelligent packaging (e.g., Greehy et al., 2011; Aday and Yener, 2015; Spence et al., 2018). There were concerns also raised about risks to consumers and society, such as whether or not it would work as advertised (e.g., Aday and Yener, 2015), if it contained components that were harmful to health (e.g., O'Callaghan and Kerry, 2016), or would cause more food waste (e.g., Pennanen et al., 2015). Consumers were also concerned about access to technologies, for example color based indicators being unable to be used by color blind consumers (e.g., Pennanen et al., 2015) and also the magnitude of change they needed to make in their purchasing habits (e.g., Lindqvist et al., 2012).

\section{Broader Psychological Moderators}

The most significant moderating variable identified in the studies was a lack of familiarity or lack of knowledge about active and intelligent packaging or nano-packaging (Stampfli et al., 2010; Greehy et al., 2011; López-Vázquez et al., 2012; Matin et al., 2012; Schnettler et al., 2014; Aday and Yener, 2015; Erdem, 2015; Gupta et al., 2015; Pennanen et al., 2015; Barska and Wyrwa, 2016; O’Callaghan and Kerry, 2016; Loučanová et al., 2018, 2019a; Nosálová et al., 2018; Daoud and Trigui, 

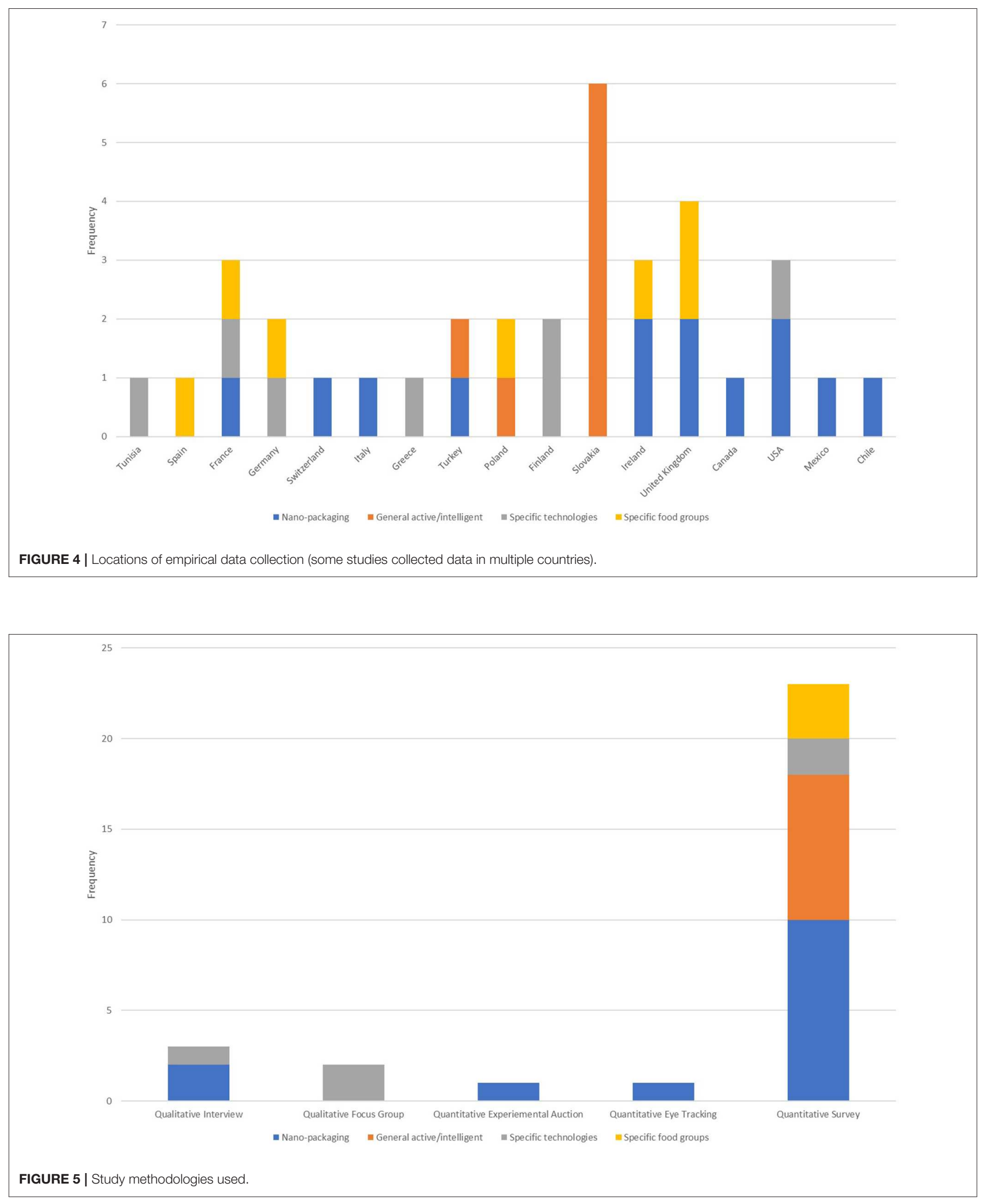


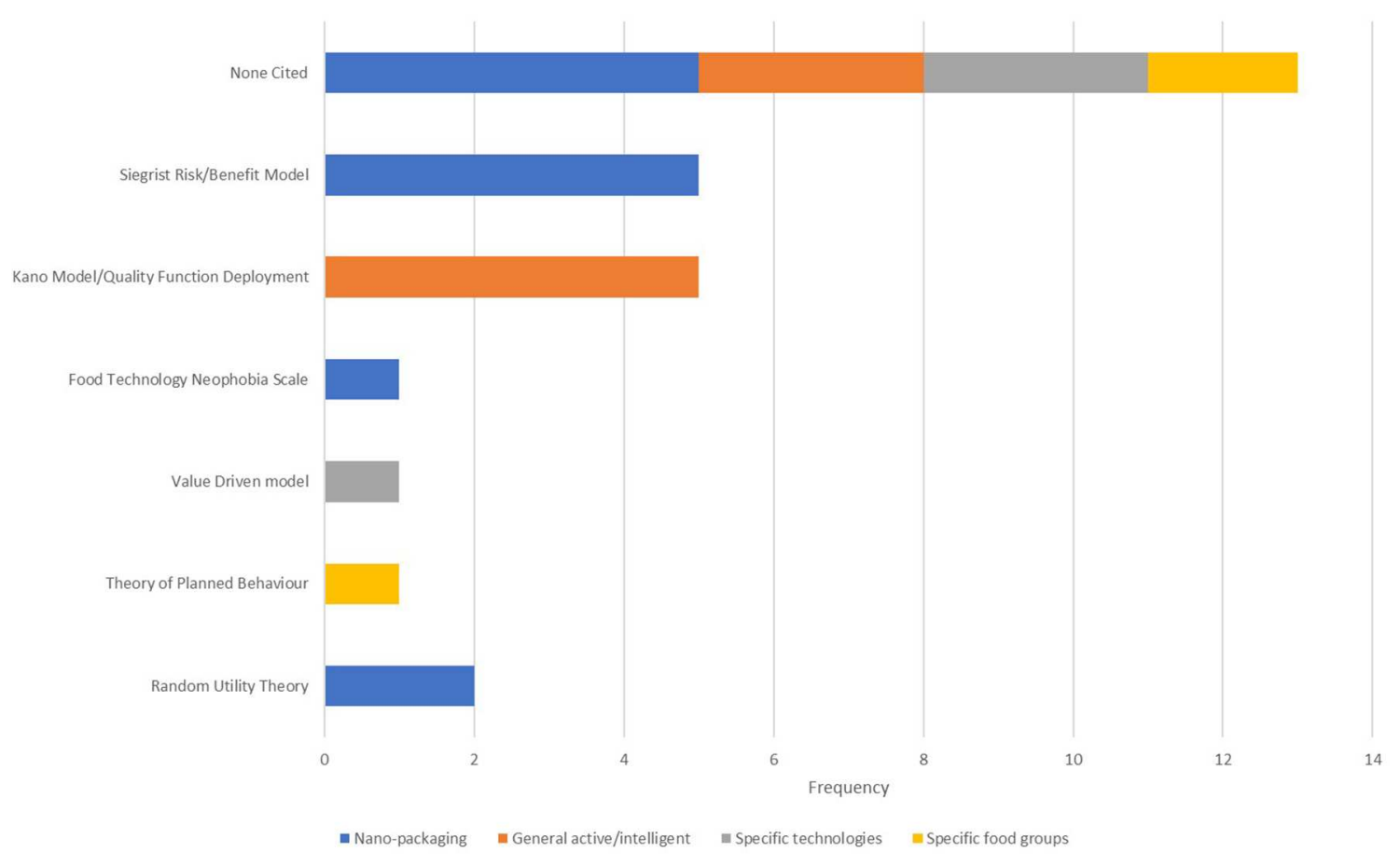

FIGURE 6 | Theories cited in eligible articles.

2019). Vandermoere et al. (2011) suggested familiarity was not related to age but was lowest amongst women and lower educated consumers (linking it to socio-demographic variables). Intelligent packaging was only familiar to $17 \%$ of respondents, and active packaging familiar to only $4 \%$ of respondents (Barska and Wyrwa, 2016). This was suggested to be due in part to general consumer ambivalence toward packaging, with many not recognizing active and intelligent packaging they had previously seen in market as being representative of such technologies. Whereas, Henchion et al. (2019) and Greehy et al. (2011) suggested that a low familiarity in food production or food industry practices in general could be related to a low familiarity with new technologies. Loučanová et al. (2018) and Erdem (2015) suggested the lack of knowledge made forming an opinion regarding benefits and risks more difficult. Related to this was lack of knowledge and understanding of food production technologies in general, such as the role of protective or helpful bacteria (Van Wezemael et al., 2011), or knowledge on the sources of risks to food safety (Vandermoere et al., 2011). The lack of familiarity was similar regardless of whether nano-packaging was researched or not.

The second most significant moderating variable was trust. Trust in the supply chain (Van Wezemael et al., 2011; Lindqvist et al., 2012; Gupta et al., 2015; Pennanen et al., 2015) including brand trust (Aday and Yener, 2015), trust in regulatory agencies (Stampfli et al., 2010; Aday and Yener, 2015; Erdem, 2015) and societal trust in general (Greehy et al., 2011; Spence et al., 2018). There was also some mistrust of the technology with a fear of misuse of RFIDs (Gupta et al., 2015), and mistrust toward
TTIs (Pennanen et al., 2015) being expressed. Spence et al. (2018) suggested that trust in government bodies was a way to engage trust in the system and technology, and that there was potentially a feedback loop between the provision of information about the product via intelligent packaging and supply chain trust. In another study, a seal of approval from governmental agencies was required for acceptance by some consumers (Aday and Yener, 2015). It was also stated that trust is a significant predictor of acceptance (Spence et al., 2018). Trust in different parts of the supply chain can vary, such as trust in researchers and consumer protection agencies can differ from trust in retailers and manufacturers (Stampfli et al., 2010), and also trust can vary significantly between countries. European consumers did not trust the packaging industry to be a provider of safe beef (Van Wezemael et al., 2011). Greek consumers had a low trust in the supply chain (Pennanen et al., 2015). Stampfli et al. (2010) also acknowledged the relationship between trust and familiarity, where trust plays a bigger role in assessing value and risks when familiarity is low.

Concepts of curiosity (O'Callaghan and Kerry, 2016; Spence et al., 2018; Daoud and Trigui, 2019), attitudes to innovations (Pennanen et al., 2015; O'Callaghan and Kerry, 2016), openness to innovation (Wilson et al., 2018) and/or a self-declaration on conservative vs. innovative lifestyle (Schnettler et al., 2014) were also presented as moderating variables. The categorizing of consumers into adopter categories by Rogers (2010) in the diffusion of innovation theory allows for these types of discussions to be grouped based on consumer interest in new technologies. In this theory consumers are 
classified with reference to their willingness to adopt new innovations/technologies as being either innovators, early adopters, early majority, late majority or laggards. For example, some respondents felt the phrase "created with innovative packaging methods" printed on the packaging was too complicated and unfamiliar leading to a lack of acceptance (Aday and Yener, 2015). Such respondents may be classified as being in the laggards or non-adopter categories.

Others consumers may not initially seek out information but become concerned about risks when prompted to think about them (Stampfli et al., 2010), or begin considering their relationship with the full supply chain rather than just the product as they develop an awareness of factors that influence food quality and safety (Pennanen et al., 2015). Other studies have suggested that consumers can be classified into several different acceptance groups (Van Wezemael et al., 2011; Wilson et al., 2018) with some wanting to know more and others not caring or not noticing that an active technology was associated with the product. Consumers who were innovators or early adopters in general were more positive and accepting of innovative packaging technologies (Greehy et al., 2011; Matin et al., 2012; Katare et al., 2016; Spence et al., 2018). Van Wezemael et al. (2011) also suggested that some socio-demographic variables correlated in part with the likely adopter categories consumers would fit into. Food neophobia is another factor that impacts on curiosity and acceptance of (or willingness to try) novel food and food production related technologies including active and intelligent packaging technologies and this can be linked to perceived naturalness (Matin et al., 2012; Sodano et al., 2016).

Consumers perceive that their personal risk is lower when they feel they have more personal control over a given situation (Frewer et al., 1995) so it is therefore logical that aspects of personal control (Greehy et al., 2011; Lindqvist et al., 2012; López-Vázquez et al., 2012; Pennanen et al., 2015; O’Callaghan and Kerry, 2016; Spence et al., 2018) over food choice and in the selection of the technologies used to manufacture food (including food packaging) moderate acceptance of active and intelligent packaging technologies.

An approach taken by Pennanen et al. (2015) and Sodano et al. (2016) is that consumers will become too dependent on technology and lose the ability to make decisions independently from it, consequently ceding aspects of control to the technology, and to food manufacturers and retailers. Providing information so active choices can be made (Greehy et al., 2011) was also an important aspect discussed.

The environmental implications of food waste vs. packaging waste, and society's response to those implications means that environmental attitudes also play a role in the acceptance of packaging, including novel packaging technologies. In general a higher environmental attitude tended to correlate, albeit weakly in some cases, to a reduced acceptance of active and intelligent packaging (Greehy et al., 2011; Matin et al., 2012; Sodano et al., 2016; Henchion et al., 2019; Loučanová et al., 2019b). Loučanová et al. (2019b) investigated such a relationship more closely, and concluded that the use of active and intelligent packaging is a "weak green strategy."
Other moderating variables discussed were; satisfaction with food related life (Schnettler et al., 2014), beliefs around societal vs. personal benefits of the technologies (Greehy et al., 2011), and subjective norms (Spence et al., 2018).

\section{Control Variables}

The control variables accounted for and discussed in the studies all tended to be sociodemographic variables. They included; home/family situation-partners and/or dependents (Greehy et al., 2011; Lindqvist et al., 2012; Matin et al., 2012; Pennanen et al., 2015; Katare et al., 2016), income levels (Lindqvist et al., 2012; Matin et al., 2012; Aday and Yener, 2015; Barska and Wyrwa, 2016; Katare et al., 2016), location (Van Wezemael et al., 2011; Lindqvist et al., 2012; López-Vázquez et al., 2012; Matin et al., 2012; Schnettler et al., 2014; Aday and Yener, 2015; Pennanen et al., 2015; Barska and Wyrwa, 2016; O'Callaghan and Kerry, 2016; Spence et al., 2018), age (Vandermoere et al., 2011; Lindqvist et al., 2012; Matin et al., 2012; Schnettler et al., 2014; Pennanen et al., 2015; Katare et al., 2016; Loučanová et al., 2016, 2017, 2018, 2019a; O'Callaghan and Kerry, 2016; Wilson et al., 2018; Henchion et al., 2019), gender (Vandermoere et al., 2011; Matin et al., 2012; Schnettler et al., 2014; Aday and Yener, 2015; Pennanen et al., 2015; Katare et al., 2016; O'Callaghan and Kerry, 2016; Sodano et al., 2016; Wilson et al., 2018; Henchion et al., 2019), education level (Greehy et al., 2011; Vandermoere et al., 2011; Van Wezemael et al., 2011; Matin et al., 2012; Aday and Yener, 2015; Pennanen et al., 2015; Katare et al., 2016; O'Callaghan and Kerry, 2016), and social class (Henchion et al., 2019).

The control variables accounted for a significant portion of the heterogeneous nature of the acceptance results. Greehy et al. (2011) states that personal circumstances influence the personal relevance of the technology, thus affecting acceptance, and (Zhou and $\mathrm{Hu}, 2018$ ) suggested that demographics as well as habits and other moderating variables can affect acceptance. For example, changing demands on food packaging in Poland has been suggested to be due to rapid economic growth which generated new consumption trends and more mobile society (Barska and Wyrwa, 2016). Matin et al. (2012) also discusses the differences between population groups between Canada and France and that the culture may have an effect on environmental attitudes, which in turn results in variation in the acceptance of novel packaging. These results suggest that differences in the hierarchy of food needs (Satter, 2007) influence the heterogeneity of the acceptance results relative to the control variables and that understanding where a population group is located on the hierarchy may assist in understanding or predicting their attitude to novel packaging technologies.

\section{DISCUSSION}

After reviewing the findings from the systematic literature review, a conceptual framework (Figure 7) was developed. It initially consisted of 5 parts: purchase intent, motives, 


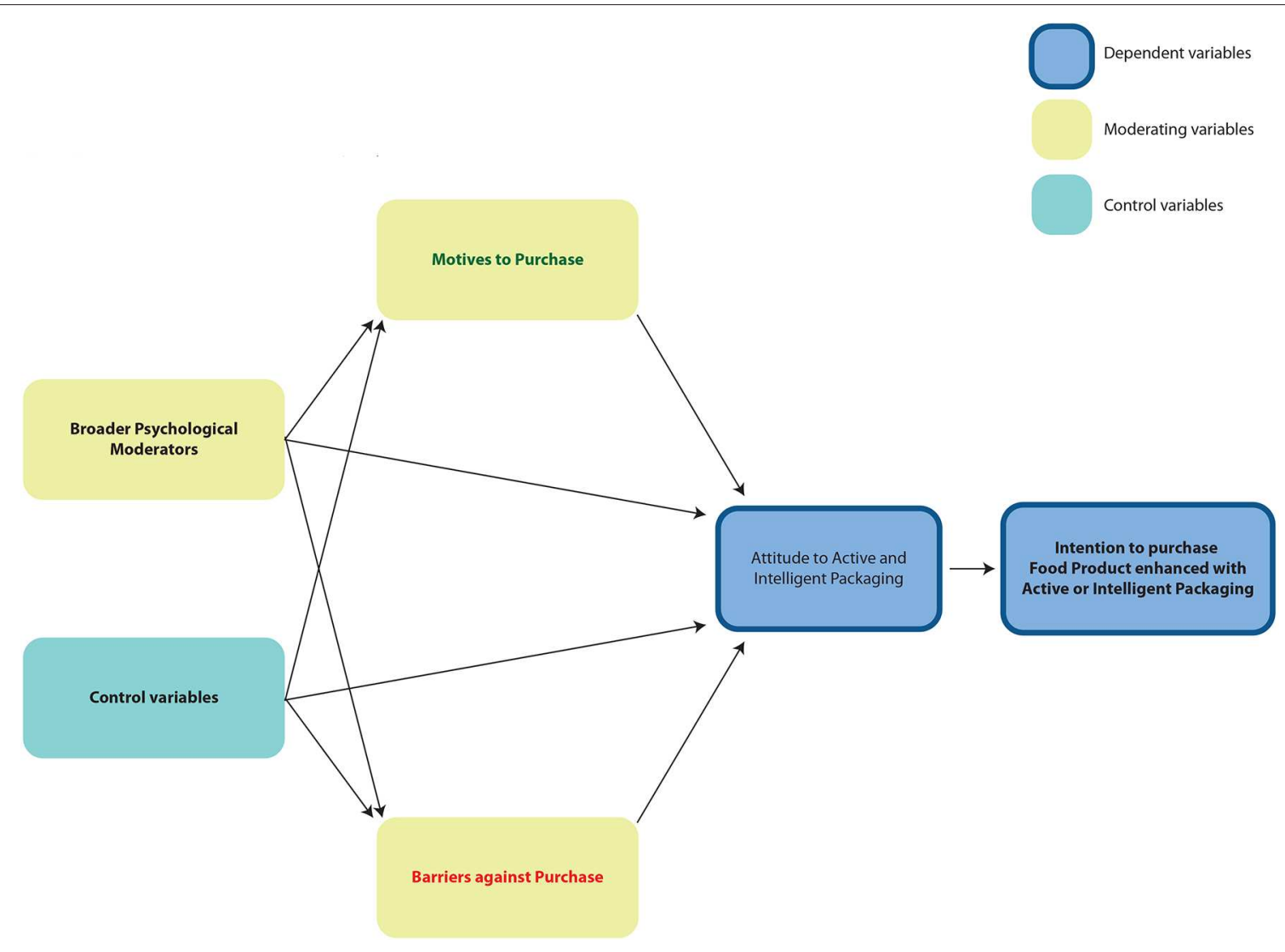

FIGURE 7 | Initial conceptual framework on motives, barriers and purchase decisions.

barriers, broader psychological moderating variables and sociodemographic control variables.

The range of reasons consumers find active and intelligent packaging potentially useful ranged from practical utilitarian reasons through to hedonistic emotional and social reasons, and the same was found with the barriers to purchase. Exploring these reasons more carefully, along with how the broader psychological moderating variables and the socio-demographic control variables influence the perception of the different values and barriers will enable a better understand of the drivers for purchase of foods enhanced with smart packaging.

\section{Value of Active and Intelligent Packaging and Motives for Purchase}

The theory of consumption values has previously been successfully used to understand consumers' reasoning to purchase organic food (Kushwah et al., 2019) and this theory was believed to also be a suitable theoretical lens for classifying different motives for purchasing foods enhanced with smart packaging technologies as the values in the technology are varied and form the basis for motives for purchase.

Packaging is an important extrinsic determinant in food choice. It provides a functional value through containing the food, protecting the safety and quality of the food, and added convenience through appropriate pack sizes and added functionality (e.g., easy open or reclose features). It also provides epistemic benefits by communicating detailed information about the product such as ingredients, origin, brand, etc. Time temperature indicators (an intelligent packaging technology) can improve safety, provide assistance and enhance interest and ease of use (Pennanen et al., 2015) aligning well with the packaging functions of protection, convenience and communication. The utilitarian functional and epistemic values are two of the motive classifications described by the theory of consumption values (Sheth et al., 1991), and form the core benefits packaging brings to food product, despite also having ancillary benefits in the other motive classifications. The ancillary benefits, are the hedonistic benefits described in Sheth et al. (1991) as emotional value and social value. Conditional value is the fifth value and is relatively self-explanatory in that values are not always beneficial all the time, so if the condition required for the benefits to manifest is not present the rest of the values are irrelevant.

Studies focused on consumer responses to active and intelligent packaging, without a focus on nanotechnology discussed the values provided by active and intelligent packaging in general (e.g., Pennanen et al., 2015; Loučanová et al., 2016; O'Callaghan and Kerry, 2016). Whereas, the studies which specifically investigated consumer responses to nano-packaging tended to focus more on the influence of perceived personal 
control of their choices and broader psychological moderating variables on how consumers perceived values provided by active and intelligent packaging (e.g., Stampfli et al., 2010; Greehy et al., 2011; Matin et al., 2012).

\section{Functional Value}

The functional benefits packaging brings to food products are centered on three of the four packaging functions [protection, convenience and containment-Robertson (2013)]. Food shelf life extension, food safety and quality improvements can be achieved through isolating the food from the agents that catalyze or directly cause the deteriorative reactions (protection and containment). Convenience attributes can include easy open features, re-closer features and in having convenient quantities of food that align with consumer consumption usage being packaged together.

The majority of active packaging technologies are focused on enhancing the functional protective value of the product thereby maintaining food safety and quality at a higher level over a longer period of time. For these reasons, functional value was the most significant value perceived by consumers across the studies, motivating purchase intent, which is a common result when utilizing the theory of consumption values (Sheth et al., 1991). The functional benefits of active and intelligent packaging were easy to understand and could be seen clearly (Pennanen et al., 2015; O'Callaghan and Kerry, 2016; Nosálová et al., 2018), with value placed on those benefits (Gupta et al., 2015). Loučanová et al. (2016) suggests that the protective function from active packaging is one dimensional in that achieving it leads to fulfillment and satisfaction, and non-compliance to dissatisfaction.

The desirability of shelf life extension as a functional benefit of active packaging was discussed by Aday and Yener (2015), O'Callaghan and Kerry (2016), Katare et al. (2016), Wilson et al. (2018), Greehy et al. (2011) and Barska and Wyrwa (2016). However, the results were mixed with some studies (Pennanen et al., 2015; Katare et al., 2016; O'Callaghan and Kerry, 2016; Nosálová et al., 2018; Wilson et al., 2018) suggesting consumers wanted a longer shelf life, which was seen to offer additional flexibility in consumption timings reducing food waste (Pennanen et al., 2015) and therefore increasing convenience (Greehy et al., 2011) but at the cost of perceived naturalness, freshness and healthiness. There were conflicting opinions, with (Aday and Yener, 2015) suggesting that consumers were happy with the current shelf life and felt little need for it to be lengthened. Aday and Yener (2015) were also in agreement with Barska and Wyrwa (2016) who found that exchanging active packaging for food additives to retain a more natural product with the same shelf life was desired.

Active packaging's protective function to extend a product's shelf life can alternatively be viewed as the provision of safer and higher quality food at any given time point in the product life. Several studies have discussed the desirability of enhanced food safety and quality (Van Wezemael et al., 2011; Aday and Yener, 2015; Barska and Wyrwa, 2016; O'Callaghan and Kerry, 2016; Nosálová et al., 2018; Wilson et al., 2018).
The benefits of which were the prevention of spoilage and fresher taste and flavor, particularly for more highly processed products (Barska and Wyrwa, 2016; O'Callaghan and Kerry, 2016). One participant commented that they wanted improved product quality and not an increase in longevity of mediocre products (Wilson et al., 2018). Other studies referred to health benefits derived from the healthier food being facilitated through active packaging (Greehy et al., 2011; Sodano et al., 2016).

Active packaging also facilitated additional convenience related functional benefits from the additional shelf life and food safety benefits such as making shopping easier by being able to buy in bulk owing to the longer shelf life achievable (Loučanová et al., 2016; O'Callaghan and Kerry, 2016), or as O'Callaghan and Kerry (2016) suggested making more highly processed foods with normally unacceptable short shelf life viable (e.g., grated cheese).

\section{Epistemic Value}

The fourth core functional benefit packaging provides food products is communication (Robertson, 2013), which aligns with providing epistemic value in the context of utilizing consumer value theory to categorize consumer recognized benefits. The epistemic value provided by packaging is primarily in satisfying the desire for knowledge about the product. In addition to the standard information printed on the packaging (e.g., brand, ingredients, date coding and weights), intelligent packaging provides more dynamic information about the history and/or quality of the product (Robertson, 2013). This review suggests that the epistemic value provided by the communication function of packaging is an important attribute involved in consumer's purchase decisions and that intelligent packaging was a useful enhancement of that functionality (Aday and Yener, 2015; Pennanen et al., 2015). Loučanová et al. (2017) suggests that higher compliance with providing product information from intelligent packaging leads to more satisfied customers, and that the communication function is linked to the consumer's first impressions of the product.

Several types of intelligent packaging technologies were discussed in the studies, including: time temperature indicators (Aday and Yener, 2015; Pennanen et al., 2015; Barska and Wyrwa, 2016) traceability indicators (Aday and Yener, 2015; Spence et al., 2018; Daoud and Trigui, 2019) freshness indicators (Aday and Yener, 2015; Barska and Wyrwa, 2016; Nosálová et al., 2018), pack integrity indicator to show leaking or tampering (Aday and Yener, 2015; Barska and Wyrwa, 2016; Nosálová et al., 2018), and headspace gas composition (Nosálová et al., 2018). The benefits cited included a belief that they confer a form of quality guarantee (Aday and Yener, 2015; Pennanen et al., 2015; Nosálová et al., 2018; Spence et al., 2018) and the perception of them resulting in safer higher quality products (Pennanen et al., 2015; Spence et al., 2018) and enhanced supply chain and retailer reliability (Pennanen et al., 2015; Spence et al., 2018). Intelligent packaging can also assist with within the home monitoring of storage temperature and/or product quality (Pennanen et al., 2015) decision making (Lindqvist et al., 2012; Pennanen et al., 2015; Loučanová et al., 2017) and provides mental shortcuts to 
assist cognitive processes (Loučanová et al., 2017). Perishable products (chilled and frozen), modified atmosphere and vacuum packed products were all identified as ones that would benefit most from intelligent packaging and the increased provision of information about the condition of the product (Pennanen et al., 2015). More highly processed products were also considered to benefit from traceability provisions proving authenticity, particularly in light of food adulteration, and counterfeiting scandals (Spence et al., 2018). The ability to monitor, then adjust food planning and to consume products prior to "going bad" via intelligent packaging links to a growing food awareness amongst consumers for decreasing food (and packaging) waste (Barska and Wyrwa, 2016).

Indirect measures of food quality were suggested as only having limited value. Pennanen et al. (2015) discussed the fact that time temperature indicators only provide information on the temperature history and require consumers have to make an additional cognitive step to connect that to the condition of the food product. For some consumers this may be of insufficient epistemic value to be considered an improvement over conventional and more familiar quality information such as the "best before" date. Pennanen et al. (2015) also discussed more ancillary benefits derived from the epistemic value provided by intelligent packaging. In particular increasing the awareness of factors (such as storage temperature fluctuations) that can have an impact on product quality and safety.

\section{Social Value}

The functional and epistemic values associated with active and intelligent packaging bring additional utility benefits to the food products they contain. Whereas, social value and emotional value are more in the realm of hedonistic benefits, and as such provide ancillary benefits to packaged food products rather than being part of the core purpose of food packaging.

Social value aligns very well with the positive half of "social norms" as defined in theory of planned behavior (Ajzen, 1991). In the case of food packaging, the only social value provided by active and intelligent packaging was centered on societal trends toward more sustainable living driving a trend toward minimizing packaging and food waste and a move toward more recyclable materials. Active and intelligent packaging can operate in this space through the reduction of food waste over and above conventional food packaging with an enhanced protective function (Greehy et al., 2011; Barska and Wyrwa, 2016; O'Callaghan and Kerry, 2016). It can also take over some of the protective functionality of petrochemical based barrier polymers to allow for reduced material use (O'Callaghan and Kerry, 2016) or allow replacement of them with more recyclable materials (Nosálová et al., 2018) such as lower barrier biological based polymers. These ideals form part of ethical purchasing and consumption behavior important to particular groups of consumers (Henchion et al., 2019).

\section{Emotional Value}

Emotional value is another ancillary benefit, much like social benefit, in that it is not one of the core packaging functions. When it comes to emotional value active and intelligent packaging, the most common emotional benefits were consumers feeling more confident about supply chain reliability and the safety of their food (Pennanen et al., 2015; O'Callaghan and Kerry, 2016; Spence et al., 2018), feeling more in control of their food choices (Greehy et al., 2011; Spence et al., 2018) and feeling like they are making wise food choice decisions (Spence et al., 2018). It has also been reported that consumers like the novelty of innovative packaging and find it to be exciting (Aday and Yener, 2015) and they feel good about the naturalness, freshness and healthiness of their food when packaging is used instead of additives (Greehy et al., 2011; O’Callaghan and Kerry, 2016; Sodano et al., 2016).

\section{Conditional Value}

Conditional value provided by food packaging is an ancillary benefit conferred by packaging rather than an intended benefit. There are two parts to conditional value, first (and most significant) packaging can neither confer nor retract any value or benefits that has not already been discussed, and that is whether or not consumers have a need for the product itself. The second part is around the level of functionality required by the consumer for any particular purchase occasion, which can manifest as intelligent packaging information being only available when consumers want it (Lindqvist et al., 2012). Wilson et al. (2018) suggests that the intended time duration between purchase and consumption will determine in part the level of functionality consumers want from their packaging. Daily shoppers do not require extensive shelf life as the food will be consumed within a day of purchase, whereas weekly or fortnightly shoppers require a longer shelf life so the food does not deteriorate before consumption.

\section{Effect of Independent Variables on Motives}

Different types of consumers can have different personal goals, and control and moderating variables can help identify different types of consumers and the importance these consumers place on the increased values active and intelligent packaging afford to the products they contain, particularly when the values align with relevant consumer goals (Greehy et al., 2011). The variance in aggregate results can be addressed by accounting for some of the control and moderating variables.

The effect of age on recognition of the functional value of active packaging appear to be in conflict between some of the articles. Wilson et al. (2018) found that increased age reduced preference whereas O'Callaghan and Kerry (2016), Loučanová et al. (2016), and Pennanen et al. (2015) suggested older consumers could see the benefit of food risk reduction with the functional value provided. This may be due to the wording of the questions asked where some participants were asked more general question about if they could see the benefits of the result (i.e., food safety risk reduction) whereas others were asked if they wanted such functional benefits.

For the epistemic value provided by intelligent packaging the articles were more in agreement in that younger consumers had a higher preference for such benefits (Pennanen et al., 2015; Loučanová et al., 2016, 2017, 2019a; O'Callaghan and Kerry, 2016). It was suggested that younger consumers had less 
life experience and that assistance with decision making, the provision of product information and a warning about potential problems they may not otherwise have identified was more helpful for them (Loučanová et al., 2017). However consumers also felt that intelligent packaging visual indicators would be helpful for older consumers with sight issues (Pennanen et al., 2015).

Very few significant gender differences were noted within the studies. Pennanen et al. (2015) and Aday and Yener (2015) both suggested that female consumers had a greater preference for the epistemic value provided by intelligent packaging. This should be explored further to understand if it is really a gender difference or if the variance is accounted for through controlling for household composition, caregiving role and dependents. There was also very little discussion on how location correlates with motives to purchase or the perceptions of benefits. Pennanen et al. (2015) studied consumers in several countries and suggested that consumers from cooler climates did not see the benefits of time temperature indicators as much as consumers from warmer climates. This can be considered logical with food safety risks increasing in warmer climates if improper handling occurs. Two types of households were seen to hold higher value for functional benefits of active and intelligent packaging. Consumers in larger households tend to buy in bulk and due to that be more interested in the functional benefits derived from active and intelligent packaging for perishable items. The other type of household was those with more vulnerable dependents like the elderly or young children. The food safety risks for the vulnerable members of the household frame the perceptions of the benefits in a more positive way (Greehy et al., 2011; Pennanen et al., 2015). Income positively correlated the value seen in functional benefits (Aday and Yener, 2015), possibly due to a correlation between income and position on the hierarchy of food needs (Satter, 2007) or the income derived ability and familiarity with outsourcing tasks like quality assessments.

Knowledge of food industry practices as well as of active and intelligent packaging specifically impacted on the values perceived. A number of studies discussed how a lack of familiarity made it difficult for consumers to assess and articulate the benefits of active and intelligent packaging (Stampfli et al., 2010; Greehy et al., 2011; Van Wezemael et al., 2011; Barska and Wyrwa, 2016), but providing specific examples mitigated this and helped consumers see the functional benefits (Pennanen et al., 2015; Nosálová et al., 2018). Other observations included a greater knowledge of food risks correlated with consumers being more optimistic about the functional benefits (Vandermoere et al., 2011), lack of familiarity correlated with consumers being more easily swayed by provided information (Matin et al., 2012) and Aday and Yener (2015) noted there was more trust for more familiar technologies, trust positively correlating with the perception of benefits (Stampfli et al., 2010; Matin et al., 2012; Öner et al., 2013). There was a feedback loop between trust and the perceived benefits of functional and epistemic values provided by active and intelligent packaging, as previously noted by Lindqvist et al. (2012), Pennanen et al. (2015), López-Vázquez et al. (2012), O’Callaghan and Kerry (2016), and Spence et al. (2018).
There was also a link between perceived personal control and conditional value (Lindqvist et al., 2012; O'Callaghan and Kerry, 2016), where having the option to opt in or out depending on need and desire was preferred by consumers. In the diffusion of innovation theory consumer are categorized based on their openness to new technologies (Ajzen, 1991). As such a higher level of curiosity (Barska and Wyrwa, 2016; O'Callaghan and Kerry, 2016; Spence et al., 2018; Daoud and Trigui, 2019) and more positive attitudes to innovations in general (Pennanen et al., 2015; Henchion et al., 2019) correlated positively with seeing functional and epistemic value in the active and intelligent packaging technologies. The engagement of consumers with the food industry in capability (Pennanen et al., 2015) and interest (Stampfli et al., 2010) seemed to correlate with consumers associating fewer benefits from active and intelligent technologies, suggesting engagement and confidence with the conventional products and packaging.

\section{Barriers Against Purchase}

As with the motives for purchasing food packaged in active or intelligent packaging, the barriers against purchase were also varied and required some form of classification and organization. Resistance to innovative packaging was also suggested to be dependent on broader issues than to a lack of experience or irrational resistance (Sodano et al., 2016). The innovation resistance theory (Ram and Sheth, 1989) was found to be a suitable lens for organizing and categorizing the barriers to purchase foods enhanced with active or intelligent packaging. The innovation resistance theory separates barriers into two groups; functional and psychological (Ram and Sheth, 1989) which mirror the utilitarian and hedonistic benefits discussed previously. Functional barriers include a usage barrier and the value barrier, psychological barriers include a perceived risk barrier, which can be broken down further to physical risk, environmental risk, functional risk and social risk, tradition barrier, and an image barrier.

\section{Usage Barrier}

Ram and Sheth (1989) have defined the usage barrier as an incompatibility with existing workflows, practices or habits, which can include practical difficulties and challenges. There were a number of usage barriers suggested in the studies. Lindqvist et al. (2012) discussed the particular concerns about downloading traceability apps to scan codes and having data coverage and availability to connect and download the information when codes are scanned. Standardization of apps and methods was also cited as a concern while this technology is in an emergent phase-consumers don't want dozens of apps on their phone with a similar purpose. Confusion using time temperature indicators was also a significant barrier for participants (Pennanen et al., 2015), from being an indirect measure of quality requiring an additional cognitive step to understanding what to do if the indicator contradicts a printed expiration, and what transitory colors mean (e.g., yellow, olive or orange in a green to red traffic light system). This study also highlighted that nontraditional colors were not intuitive but 
green/red intuitive systems were not suitable for use by color blind consumers.

\section{Value Barrier}

Another functional barrier is cost, or the value proposition in terms of performance to price compared with alternatives solutions. If there is no improvement in the value proposition, there is no motive to change (Ram and Sheth, 1989). Aday and Yener (2015), Barska and Wyrwa (2016), Greehy et al. (2011), Spence et al. (2018), Schnettler et al. (2014) and Pennanen et al. (2015) all discussed the trade-off between additional benefits provided by active and intelligent packaging and the assumed increased costs to consumers to implement, and how this was a barrier to the success of the innovation. Both Greehy et al. (2011) and Pennanen et al. (2015) cited current food costs and the inability to pay by some groups within the community as a barrier beyond simply the value proposition. Pennanen et al. (2015) also confirmed that customers chose active and intelligent technologies when the price was approximately the same whereas O'Callaghan and Kerry (2016) confirmed the concern that shelf life benefits could not justify an increased cost where the food product was already expensive. Lindqvist et al. (2012) cited the additional ancillary cost of data cost for receiving the information about the product when scanning traceability codes as a barrier, while Nosálová et al. (2018) suggested that consumers want economical packaging that uses a reasonable quality of resources without an enormous price increase to gain the additional value from active and intelligent packaging. However, Schnettler et al. (2014) identified a group of consumers that associated higher price with better quality meaning that cost was less of a barrier for them.

\section{Risk Barrier}

The uncertainties inherent in innovation can be clustered together as the "risk barrier" and include the unknowns and potential side effects that cannot be anticipated (Ram and Sheth, 1989). Postponing the adoption of an innovation to allow for better risk identification is an approach taken by many consumers. Study participants raised concerns about risks (Erdem, 2015), and speculated that they could have unknown effects on health, and the environment (Gupta et al., 2015; O'Callaghan and Kerry, 2016), suggesting the need for economic incentives to counteract the perceived risks. Risk can be organized into four categories: physical risk, economic risk, functional risk and social risk.

Physical risk is related to harm to people or property (including the environment at large) that may be inherent in the innovation (Ram and Sheth, 1989), the potential for which concerned some consumers (Gupta et al., 2015). Consumers in the studies were concerned about the toxicity of materials used in intelligent packaging indicators (Pennanen et al., 2015; Barska and Wyrwa, 2016) and the accidental ingestion of active packaging sachets, or of the sachet contents if they disintegrated (Aday and Yener, 2015). The toxicity of nano-scale components and their possible ingestion was also noted and nano-packaging was cited as a possible physical risk and as such physical risk was expected to be more comprehensively discussed by the studies focused on nano-packaging but this was not the case. However, it was discussed that consumers wanted management of physical risk from nano-scale components via increased regulations to minimize that risk (Sodano et al., 2016; Henchion et al., 2019). The physical risks perceived to be introduced by the technologies counteract the overall food safety physical risk reduction achieved by the active packaging technologies. The question of "who takes the risks vs. who receives the benefits?" was asked (O'Callaghan and Kerry, 2016) suggesting that whomever takes the risks should reap the benefits. Other consumers took a more fatalistic view minimizing the physical risks in their minds to focus on the benefits of the technologies (Greehy et al., 2011). Despite that, Greehy et al. (2011) stated that physical risk should be minimized prior to product launch. Another form of physical risk cited by Gupta et al. (2015), was that advanced technologies like RFID have the potential to be invasive and/or replace jobs. Physical risk can also affect property or the environment. The use of active and intelligent packaging can affect the environment in terms of food waste increases (Aday and Yener, 2015; Gupta et al., 2015; Pennanen et al., 2015), implications for packaging recyclability and changes to packaging waste form part of the equation for environmentally aware consumers and legislators

Economic risk is next type of risk, and is defined as relating to the perceptions of performance to price ratio of new innovations in that early stage where the innovation is costly and that updated versions will learn from early mistakes and be both cheaper and better (Ram and Sheth, 1989). Economic risk is more relevant to higher priced capital goods rather than fast moving consumer goods like food. There was no significant discussion on economic risk in any of the articles reviewed over and above that already discussed as part of the value barrier.

Functional risk is related to performance uncertainty (Ram and Sheth, 1989) which means in the case of active and intelligent packaging, the risk that the packaging does not provide the benefits to product protection and product information that it has promised. As a new technology there were several articles (Pennanen et al., 2015; O'Callaghan and Kerry, 2016; Wilson et al., 2018) discussing consumer concerns about functional risk. Specific concerns raised included not believing a quality improvement could come from the inclusion of an active packaging sachet (Wilson et al., 2018), questions about where TTIs work the same for all kinds of products (Pennanen et al., 2015), and the correct action to take was if a TTI conflicted with a "best before" date (Pennanen et al., 2015). More general concerns were also raised about general reliability and whether they would work (Pennanen et al., 2015; O’Callaghan and Kerry, 2016), with Barska and Wyrwa (2016) stating that there was significant skepticism that active and intelligent packaging solutions worked at all. Presenting novel technologies under the guise of familiar brands has the potential to reduce risk perception and increase acceptance (Schnettler et al., 2014; Aday and Yener, 2015; Henchion et al., 2019).

The final type of risk discussed is social risk, this risk is the concern as to what others will think, and if as a consumer they will face social ostracism or peer ridicule for utilizing an innovation (Ram and Sheth, 1989). With regard to active and 
intelligent packaging, this concept was not discussed in the articles reviewed.

\section{Tradition Barrier}

Consumers have tradition and habits, and when an innovation requires change from tradition, the magnitude of that change correlates with the magnitude of resistance (Ram and Sheth, 1989). The habit of buying products in conventional packaging can be a barrier (Barska and Wyrwa, 2016), as is the compatibility of new technologies with current food assurance habits (Spence et al., 2018). A specific example would be that checking or scanning intelligent packaging codes is time consuming and a new habit (Lindqvist et al., 2012). Food packaging has certain consumer perceived attributes that shape opinions of novel packaging technologies, which can be barriers to purchasing foods incorporating active and intelligent packaging. Packaging and technology ambivalence is a significant tradition barrier to overcome that is discussed in O'Callaghan and Kerry (2016), Schnettler et al. (2014), Pennanen et al. (2015), Erdem (2015), Gupta et al. (2015), Greehy et al. (2011), Loučanová et al. (2016), Loučanová et al. (2017), Zhou and Hu (2018) and Van Wezemael et al. (2011). One study suggested that packaging is simply not as exciting or interesting as the food product itself (Greehy et al., 2011). Alongside packaging ambivalence, many consumers felt that active and intelligent packaging technologies were not necessary, even to the point of being over the top and therefore its use was not a purchase driver (Greehy et al., 2011; Aday and Yener, 2015; Erdem, 2015; Pennanen et al., 2015; O'Callaghan and Kerry, 2016; Loučanová et al., 2018). In some cases alternative and current solutions to the benefits active and intelligent packaging bestow on food products were preferred by consumers (Henchion et al., 2019). Printed expiry dates were preferred over TTIs (Pennanen et al., 2015; Barska and Wyrwa, 2016), and in another study (Van Wezemael et al., 2011) the idea of changing packaging characteristics to enhance the safety of beef was rejected by a proportion of the study participants.

\section{Image Barrier}

The final psychological barrier in the innovation resistance theory is image. Ram and Sheth (1989) state that any innovation derives part of its identity from the technologies it originates from. In the case of active and intelligent packaging, food packaging in general and consumer opinions of it influence their opinions of newer technologies. Active and intelligent packaging opinions can also be influenced by other new food production and processing technologies such as genetic modification, particularly when consumers lack familiarity with novel packaging technologies. One of the most significant concerns cited in the studies reviewed was the environmental cost of single use packaging. Greehy et al. (2011) states that consumers are concerned that active and intelligent packaging technologies may prevent the use of biodegradable materials, or make materials less recyclable than currently possible, and Matin et al. (2012) stated that participants see packaging as bad for the environment so innovative packaging is seen to be even worse. The use of less packaging regardless of technology is preferred by environmentally conscious consumers (Henchion et al., 2019).
Perceived naturalness is another aspect of image barrier. Food additives increase the shelf life of packaged food but reduce their perceived naturalness, so alternatives such as active packaging can be perceived as retaining naturalness while extending shelf life and thus an improvement, however for others the mere act of extending shelf life by any means is considered unnatural (Greehy et al., 2011; López-Vázquez et al., 2012; O’Callaghan and Kerry, 2016; Sodano et al., 2016). Sodano et al. (2016) suggested that the perception of naturalness is an antecedent of risk perception, and Van Wezemael et al. (2011) discussed that additives released by active packaging materials may be considered in the same light as food additives in general. Other concerns raised around perceived naturalness was the use of the word "technology" when referring to nanotechnology enhanced packaging (Greehy et al., 2011) and also the use of sachets to deliver active technologies where consumers didn't want to see anything other than the food product with the packaging (Aday and Yener, 2015). Nanotechnology, as an enabling technology for active and intelligent packaging is also a relatively novel and unknown technology and as such is assumed to have the same risks as genetically modified organisms (Gupta et al., 2015).

\section{Effect of Independent Variables on Barriers}

Control and moderating variables can help identify different types of consumers and the importance different types of consumers place in the various barriers reducing purchase intent for products augmented with active and intelligent packaging. The variance in aggregate acceptance results can be addressed by accounting for some of the control and moderating variables.

Increased age positively correlated with the increasing influence of usage and tradition barriers (Lindqvist et al., 2012; Pennanen et al., 2015), which was suggested to be due to habits being more highly entrenched with age and owing to older people being less likely to own the required technology to interact with traceability codes. Very few gender differences were identified on the perceptions of barriers to purchase food enhanced with active and intelligent packaging. Female participants were more concerned about physical risk (including ingestion of active sachets), which was speculated to be more due to the stereotypical career role than to gender per se (Aday and Yener, 2015; Wilson et al., 2018). While women appeared to like to see new packaging types (men had higher levels of ambivalence), it was also suggested by Wilson et al. (2018) that women were more experienced in making food freshness determinations while shopping and felt that active packaging sachets were not necessary and that their inclusion actually reduced their ability to make freshness determinations. Location was another independent control variable that was discussed in only a few of the studies reviewed. Location was linked to both the tradition barrier and the image barrier as well as the physical risk perception barrier. Pennanen et al. (2015) discussed the perception of necessity (tradition barrier) being related to location climate, whereas O'Callaghan and Kerry (2016) suggested that different cultures (and therefore locations) have different traditions that will impact upon the tradition barrier differently. Matin et al. (2012) linked location with the perception of naturalness (image barrier) and the influence both 
had on physical risk perception. Income level was reported to negatively correlate with the value barrier (Lindqvist et al., 2012), and the household composition was reported to influence both usage and tradition barriers. Household composition also had implications for perceptions of physical risk (Greehy et al., 2011), primarily around the framing of risk for self, vs. more vulnerable dependents.

More focus was placed on the influence of moderating variables than on the importance of the various barriers to purchase. The relationship between familiarity and the physical risks was significantly discussed with all relevant studies (Stampfli et al., 2010; Greehy et al., 2011; Van Wezemael et al., 2011; Erdem, 2015; Gupta et al., 2015; Pennanen et al., 2015; O'Callaghan and Kerry, 2016; Sodano et al., 2016; Henchion et al., 2019) agreeing that lower familiarity correlates with a higher barrier derived from perception of physical risks, the majority of these studies were focused on nanotechnology suggesting that the use of nanotechnology to achieve the aims of active and intelligent packaging is at higher risk of being influenced by this barrier. Several studies identified that making risk determinations were more difficult when there was a lower level of familiarity (Greehy et al., 2011; Van Wezemael et al., 2011) so assumptions were made based on similar technologies such as genetic modification (Stampfli et al., 2010; Gupta et al., 2015; O'Callaghan and Kerry, 2016; Sodano et al., 2016) or based speculation, confusion or misunderstanding about how the technology may work (Greehy et al., 2011; Gupta et al., 2015; Pennanen et al., 2015). Familiarity also negatively correlated with functional risk in several studies (Van Wezemael et al., 2011; Erdem, 2015; O'Callaghan and Kerry, 2016), where the lower the familiarity, the more skeptical consumers were about the technology actually working. There were also correlations identified where lower familiarity was linked to higher value (Aday and Yener, 2015), tradition [where active packaging was regarded as redundant (O'Callaghan and Kerry, 2016)], and image [perceived naturalness of the product (O'Callaghan and Kerry, 2016)] barriers. There was also some discussion on the fact that disclosing the potential of physical risks may increase trust, in a feedback loop where the perceptions of those risks was then reduced as trust increased (Öner et al., 2013) but in general a negative correlation between trust and perceived risk was discussed (Stampfli et al., 2010; Greehy et al., 2011; Öner et al., 2013; Aday and Yener, 2015; Pennanen et al., 2015). Öner et al. (2013) discussed that trust in the management of the perceived physical risks can be more important than belief in the technology itself when it comes to technology acceptance. Personal control influences perceptions on the necessity of active and intelligent packaging (tradition barrier), with consumers feeling that they had sufficient control to select the freshness, quality and safety they required (Greehy et al., 2011). Both López-Vázquez et al. (2012) and Stampfli et al. (2010) suggest that personal control also influences the perception of physical risks-consumers who can actively choose whether or not to purchase a product see physical risks as being less of a concern. Other moderating variables were connected to the diffusion of innovation theory consumer categories logically correlating with tradition barrier (Stampfli et al., 2010), and the preference for healthy food positively correlating with physical risk perception (O'Callaghan and Kerry, 2016).

\section{Acceptance and Willingness to Pay}

Attitude, acceptance and willingness to buy, and pay, for food enhanced with active and intelligent packaging technologies were the dependent variables in the studies reviewed. The ultimate aim for expert proponents of these technologies is to influence and maximize acceptance and purchase intent. It is assumed that any differences between acceptance and willingness to buy are due to variables that are outside the scope of this study and the two variables correlate significantly, so the terms are used interchangeably in the following discussion.

There were significant positive correlations between the motives for and benefits to purchasing foods with active and intelligent packaging and acceptance of those technologies (Stampfli et al., 2010; Greehy et al., 2011; Schnettler et al., 2014; O'Callaghan and Kerry, 2016; Sodano et al., 2016; Loučanová et al., 2018; Nosálová et al., 2018; Zhou and Hu, 2018; Henchion et al., 2019). Greehy et al. (2011) commented further that it was the characteristics of the benefits that impacted the level of acceptance, whereas Stampfli et al. (2010), Sodano et al. (2016) and Henchion et al. (2019) suggested that the correlation between perceived benefits and the variance in willingness to buy was much stronger than the negative correlation between perceived risk and variance in willingness to buy. Stampfli et al. (2010) also suggested that attitude to the technology was a strong variable in explaining the perception of risk and benefits, however it must be questioned as to the causality direction of the correlation, if there was one. There was very little discussion as to what form the benefits took, so it is assumed that the utilitarian benefits of functional and epistemic value were the focus.

As expected there was also significant negative correlation between the barriers and risks for purchasing food with active and intelligent packaging and acceptance of those technologies (López-Vázquez et al., 2012; Aday and Yener, 2015; Pennanen et al., 2015; Spence et al., 2018; Zhou and Hu, 2018; Henchion et al., 2019). Aday and Yener (2015), Zhou and $\mathrm{Hu}$ (2018) and Pennanen et al. (2015) all confirmed that if there was no value barrier participants would choose the innovative packaging. There was also discussion in several articles on both functional and physical risk, and particularly with adequately addressing and managing to minimize physical risk was a requirement for consumer acceptance (Greehy et al., 2011; Vandermoere et al., 2011; Spence et al., 2018; Henchion et al., 2019).

Familiarity positively correlated with acceptance of foods with active or intelligent packaging enhancements (Vandermoere et al., 2011; Van Wezemael et al., 2011; Matin et al., 2012; Barska and Wyrwa, 2016; O'Callaghan and Kerry, 2016; Wilson et al., 2018; Daoud and Trigui, 2019). The lack of familiarity make it difficult to accurately evaluate positive and negative information to make an informed decision (Loučanová et al., 2018, 2019b) with consumers making assumptions about risks in the absence of information (Gupta et al., 2015). Katare et al. (2016) discussed that the lack of pre-existing knowledge made 
consumers more vulnerable and more highly influenced by the provision of information.

An individual's attitude and curiosity toward technology in general also appeared to positively correlate with the acceptance of active and intelligent packaging (Greehy et al., 2011; Vandermoere et al., 2011; Van Wezemael et al., 2011; Schnettler et al., 2014; Pennanen et al., 2015; Spence et al., 2018; Wilson et al., 2018). Social and supply chain trust also positively correlated with acceptance (Stampfli et al., 2010; Matin et al., 2012; Öner et al., 2013; Schnettler et al., 2014; O'Callaghan and Kerry, 2016; Sodano et al., 2016). There was some conflict between studies as to whether there was a direct path between trust and willingness to buy or whether it was indirect through affect or motives and barriers; Öner et al. (2013) stated that there was no direct path, Sodano et al. (2016) confirmed that there was disagreement within the literature and Stampfli et al. (2010) confirms the importance of trust regardless of whether the path is direct or indirect.

Other moderating variables that were cited to directly influence acceptance or willingness to buy were; perceived autonomy-positively correlated (Spence et al., 2018), food neophobia-negatively correlated (Matin et al., 2012; Sodano et al., 2016), satisfaction with food related life-positively correlated (Schnettler et al., 2014), focus on animal welfare positively correlated (Erdem, 2015), environmental focusnegatively correlated (Vandermoere et al., 2011) and perceived benefits to society was a positive correlation (Greehy et al., 2011). These results were predominantly logical, it is suspected that the negative correlation from environmental focus had more to do with packaging in general than the novel technologies themselves. The animal welfare correlation was unexpected and is possibly due to intelligent packaging imparting quality beyond the specific epistemic value it was directly related to.

As with the moderating variables, many of the eligible articles linked the socio-demographic control variables directly to acceptance and willingness to buy as well. Schnettler et al. (2014), Henchion et al. (2019) and Zhou and $\mathrm{Hu}$ (2018) all found no significant differences in acceptance based on sociodemographic differences, a result that is in conflict with many of the other articles where differences were identified. Most studies (Vandermoere et al., 2011; Matin et al., 2012; Katare et al., 2016; Wilson et al., 2018; Loučanová et al., 2019a) that identified a relationship between age and acceptance, suggested that younger consumers were more supportive, and had a higher willingness to pay. In contrast Loučanová et al. (2017) suggested that while younger consumers were more orientated toward intelligent packaging, older consumers were more accepting of active packaging technologies.

The correlation between gender and acceptance of foods enhanced with active and intelligent packaging was very much in conflict between the studies reviewed. Wilson et al. (2018) and Katare et al. (2016) found women were more willing to pay for active and intelligent technologies, whereas Vandermoere et al. (2011) and Sodano et al. (2016) found men more accepting of the technologies. Further investigation is needed to determine the cause of this conflict, whether it was the result of different survey questions or whether other variables are at play.
Income had a positive correlation with technology acceptance where differences were found (Van Wezemael et al., 2011; Barska and Wyrwa, 2016; Katare et al., 2016), as such it was suggested that commercial success would be more difficult in lower income areas (Barska and Wyrwa, 2016) if there is a value barrier involved in the introduction of novel technologies. Where differing results were found, education levels was also consistently positively correlated to acceptance of active and intelligent packaging enhancements to food products (Vandermoere et al., 2011; Van Wezemael et al., 2011; Katare et al., 2016). These results were suspected to be more due to a lack of familiarity likely to be more prevalent in lower income consumers rather than the lower income itself.

Household composition/size had a positive correlation with acceptance of active and intelligent packaging (Greehy et al., 2011; Matin et al., 2012; Katare et al., 2016). It is likely this is due to framing how the benefits are useful for dependents influenced acceptance rather than a direct link between the variables. Location, in the form of climate, positively correlated with acceptance (Van Wezemael et al., 2011; Aday and Yener, 2015) again this is suspected to be due to a higher functional value for both active and intelligent packaging in warmer climates. Schnettler et al. (2014) also suggested that developed and developing countries differ, which requires further investigation under the hypothesis that socio-demographic variance can be explained by the hierarchy of food needs (Satter, 2007).

Overall, consumers could see that active and intelligent packaging is both beneficial and has risks involved (Öner et al., 2013) and significant variance was found (Gupta et al., 2015). The final result for acceptance and willingness to buy ranged from neutral (Van Wezemael et al., 2011; Zhou and Hu, 2018; Henchion et al., 2019) to accepting and interested (Stampfli et al., 2010; Greehy et al., 2011; Vandermoere et al., 2011; Schnettler et al., 2014; Erdem, 2015; Gupta et al., 2015; Pennanen et al., 2015; O’Callaghan and Kerry, 2016; Nosálová et al., 2018; Spence et al., 2018; Wilson et al., 2018; Daoud and Trigui, 2019; Loučanová et al., 2019a,b). Advantages cited were that active and intelligent packaging represent a competitive advantage for providing desired functional and/or epistemic value (Loučanová et al., 2018; Nosálová et al., 2018). There did not appear to be a significant difference in acceptance between the studies focused on nano-packaging and those that did not.

Aday and Yener (2015) reported a higher acceptance for intelligent packaging over active packaging, whereas Nosálová et al. (2018) suggested the interest in active packaging is higher than in intelligent packaging. When consumers were asked about specific technologies, some were found to be unacceptable including a food safety sensor not appealing to some population groups (Henchion et al., 2019), or bio-agents in meat packaging (Van Wezemael et al., 2011), nano-packaging was acceptable but RFID raised ethic privacy questions and was found to be unacceptable (Gupta et al., 2015). The conflict between the studies by Aday and Yener (2015) and Nosálová et al. (2018) could potentially be explained as a function of the survey and the specific examples given to consumers in the respective studies and the polarizing effect they may have had on the results. 
For some consumers, price increases of up to $10 \%$ were acceptable for the additional benefits obtained from the novel packaging technologies (Aday and Yener, 2015; Erdem, 2015; Barska and Wyrwa, 2016; Nosálová et al., 2018; Wilson et al., 2018).

\section{Integrated Framework on Motives, Barriers and Purchase Decisions}

In reviewing the categorized motives, or values provided to food products by smart packaging, and the categorized barriers to purchase it was noted many eligible studies in this review linked some of the moderating variables directly to purchase intent and when looking to identify the relationships already tested, the framework became difficult to manage. So alternative options for organizing the conceptual framework were investigated, with the thought of separating influences on behavior from attitude formation (Figure 8). Chen (2008) utilizes the theory of planned behavior (TPB), and integrates it with an attitude model to expand the attitude to technology portion of the TPB to build a full framework for consumer purchase intent for genetically modified foods.

In utilizing the theory of consumption values and innovation resistance theory as the theoretical lens for discussing the motives and barriers respectively, an adjustment was needed to link the attitude model and theory of planned behavior and remove duplication. Social value and social risk from the theory of consumption values and innovation resistance theory respectively were felt to align better with the positive and negatives sides of subjective norms as a behavior driver rather than attitude driver, so were moved from the barriers and motives influencing attitude to within social norms in the behavior portion of the model. Correlations have been discussed for many of the relationships between the boxes in the model. In general the motive variables had a positive impact on attitude and the barriers box has a negative effect on attitude. The relationships between the control variables and the moderating variables to the motives, barriers, and attitude were complicated. Some had positive correlations, some negative, and some studies were in conflict with each other. This model differs from that of Siegrist et al. (2007), in that attitude is dependent on the perceptions of benefits and risks rather than vice versa.

Expanding the theory of planned behavior by utilizing the theory of consumption values and innovation resistance theory as the theoretical lens for classifying the benefits and risks that feed into attitude, assists the integrated model to address some of the criticisms of the theory of planned behavior as it would

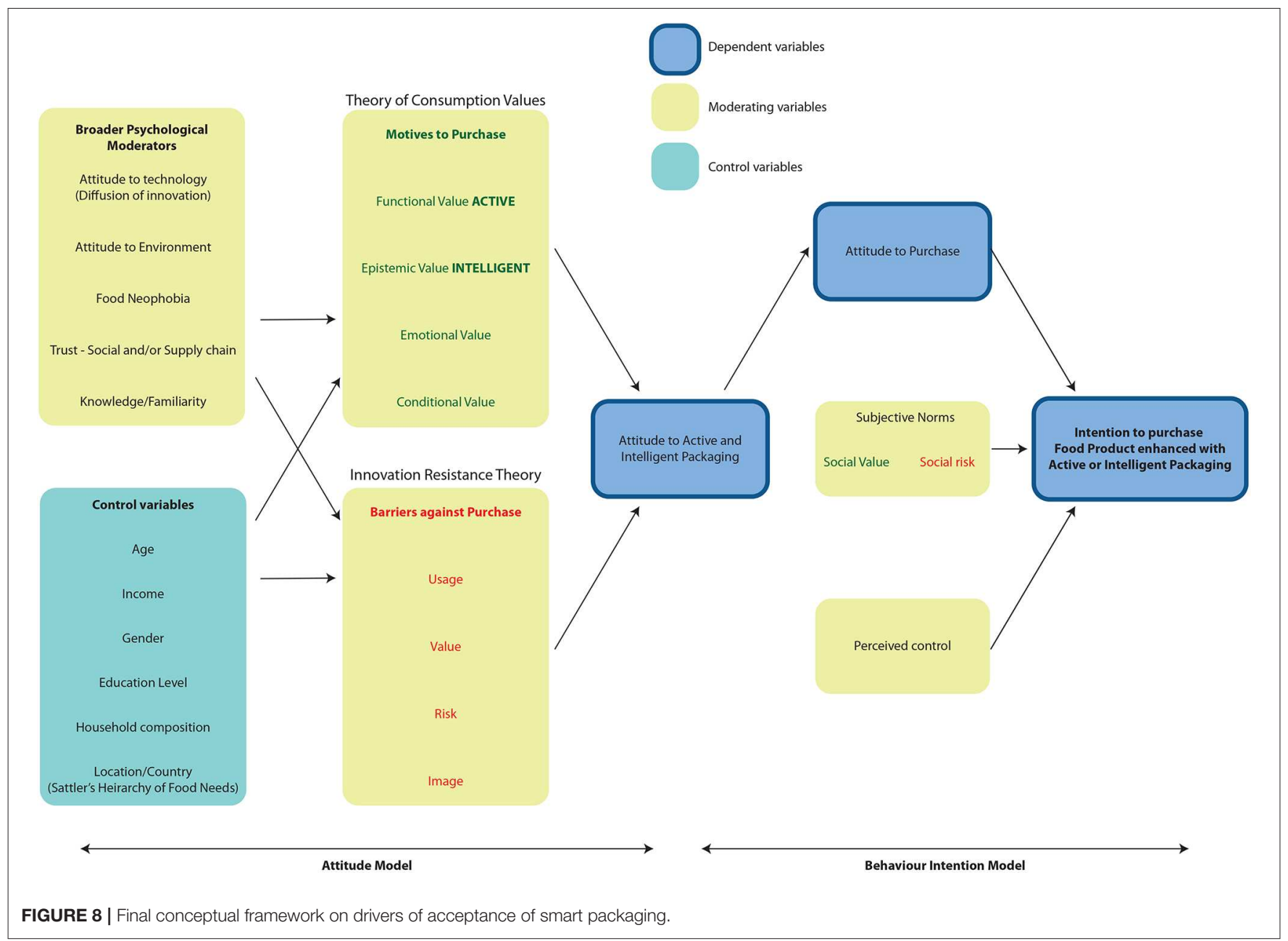


normally stand, in particular the concern that "habit" forms part of the tradition barrier.

Consumers have detailed and complicated relationships with food, as confirmed by food consumer values presented by Dagevos and van Ophem (2013). The approach used here for this conceptual framework incorporates both utilitarian and hedonistic benefits as well as functional and psychological barriers recognizing that food must be treated as being than more than just a commodity.

\section{Implications, Limitations and Future Work Implications for Developing Active and Intelligent Packaging Propositions}

The findings of this systematic literature review are somewhat fragmented with significant coverage holes (particularly with regard to global location), and as such very few generalizations can be made (Figure 9). There are however, some practical implications from the few generalizations that can be made that will enable experts involved in developing and promoting active and intelligent packaging to maximize acceptance.

Familiarity is low for active and intelligent packaging, which if not counteracted by educational communication will result in the rejection of food products. An example cited by Wilson et al. (2018) discussed the inclusion of an active packaging sachet in cut cantaloupe packaging, which was not well received by consumers prior to an explanation of its purpose.

Utilizing the emotional value tied up in well-known brands can reduce risk perception and increase acceptance (Schnettler et al., 2014; Aday and Yener, 2015; Henchion et al., 2019).

In general the provision of information to consumers about the packaging technology will increase trust (as it indicates openness), which improves attitude (Greehy et al., 2011; LópezVázquez et al., 2012; Aday and Yener, 2015; Katare et al., 2016; Wilson et al., 2018) and reduces risk, particularly for consumers that have little knowledge and therefore only weakly made opinions about the technology (Katare et al., 2016). Sodano et al. (2016) suggests communication needs to focus on more than simply the functional benefits and risks. But also account for the social, cultural and recreational aspects of food consumption. Greehy et al. (2011) also stated that despite that caution, focusing on benefits, while highlighting downsides of alternative and retaining transparency on risk is the proposed solution to maximize acceptance. The objective is to re-frame consumer attitudes to bridge the gap between risks and benefits, and increase trust (Sodano et al., 2016; Loučanová et al., 2018; Wilson et al., 2018).

Proactively engaging with government agencies and regulators assists in building trust through carefully considered regulation to ensure physical risks are minimized (Henchion et al., 2019), in addition acceptance can be provisional on comprehensive labeling (Greehy et al., 2011). Communication methods may include commercials, advertising, media (Aday and Yener, 2015) and social media.

Some recognition of different tools and provision of information will minimize barriers in different ways and increase perceptions of benefits also in different ways (Stampfli et al., 2010; López-Vázquez et al., 2012), and can be used to target particular desired consumer groups (Loučanová et al., 2016, 2017 , 2018). These tools can be addressed by communication from regulatory bodies as well as manufacturers themselves and will influence consumers to a greater or lesser effect. Sodano et al. (2016) suggested that managing the precautionary principle by avoiding mandatory labeling and balancing the disclosure of the risks with the benefits so to avoid that risks and labeling be interpreted as a potential danger, which will consequently reduce willingness to purchase. If familiarity is low, education must play a significant part (Matin et al., 2012) in the communication message. Phrasing of communication needs to be carefully considered, as different phrasing can have significant impact on acceptance (Van Wezemael et al., 2011) e.g., bacteria being perceived as bad even if prefaced with a "good" word like "protective"), and this should be taken into account when developing communication strategies.

Value barriers can also be reduced through increasing familiarity with free samples (Aday and Yener, 2015), in addition to the communication strategies discussed above.

\section{Limitations and Future Work}

The eligible studies analyzed as part of this systematic review outlined limitations to their studies and also made recommendations on future work. This review is no exception to that, with both limitations and recommended future work being outline below.

There are limitations to this systematic review that ideally will be addressed in future work. There were a very limited number

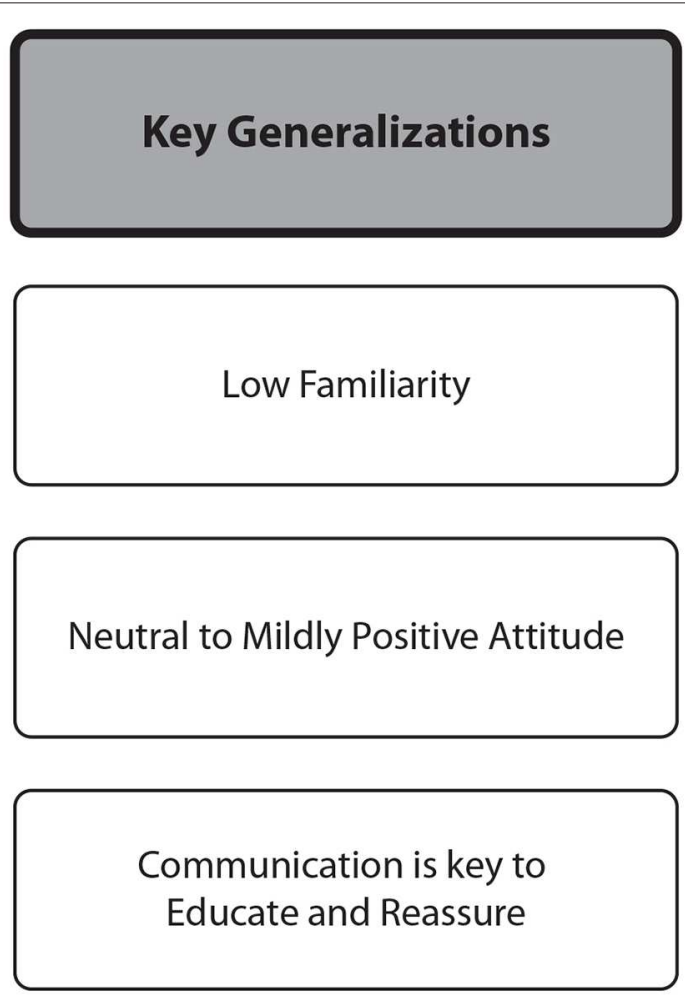

FIGURE 9 | Key generalizations. 
of studies that met the inclusion criteria, and the majority of them were quantitative, taking a "reductionist" approach with surveys, and very little multi-disciplinary observational exploratory work so critical building blocks for this conceptual framework have the potential to be absent. This study was qualitative in nature, exploring the themes generated across the studies but this approach may have added bias to the findings. The limited number of studies, the limited geographic spread, and that the included studies focused on limited parts of the integrated model meant that the full model was not explored sufficiently comprehensively to achieve good confidence in its accuracy. Limitations from the included studies that may have a flow on effect to this review include: there were relatively small sample sizes (Greehy et al., 2011; Erdem, 2015; Katare et al., 2016; Sodano et al., 2016), limited geographic regions (López-Vázquez et al., 2012; Öner et al., 2013; Schnettler et al., 2014; Aday and Yener, 2015; Katare et al., 2016), age range not representative (López-Vázquez et al., 2012), nonprobability sampling (Vandermoere et al., 2011; Öner et al., 2013; Schnettler et al., 2014), exclude consumers without internet access (Vandermoere et al., 2011; Pennanen et al., 2015), limited survey design (Vandermoere et al., 2011; Van Wezemael et al., 2011; Matin et al., 2012; Spence et al., 2018), influence of information provided (Greehy et al., 2011), the use of specific applications could have influenced the generalizability of the results (Öner et al., 2013; Gupta et al., 2015) and hypothetical situations rather than real purchases (Stampfli et al., 2010; Greehy et al., 2011; Pennanen et al., 2015).

Consumer acceptance of active and intelligent packaging is not a well-researched area so there are many areas to investigate more deeply, such as a covering a broader geographical spread, understanding if the hierarchy of food needs explains the heterogeneous results relative to socio-demographic control variables, or understanding the diffusion of innovation theory explains the influence of curiosity and attitudes to innovation reflected in the acceptance of active and intelligent packaging. Better understanding of how the use of nanotechnology to deliver active and intelligent packaging objectives influences acceptance also needs to be further researched. Empirical testing of the full conceptual framework with a sample population is also needed, as well as applying it to specific technologies and specific food groups to test the breadth of applicability.

Future work recommended in the studies reviewed included: longitudinal studies (Vandermoere et al., 2011), investigating attitudes to nature more deeply (Matin et al., 2012), increasing the geographical spread of the studies including addressing cultural questions (Vandermoere et al., 2011; López-Vázquez et al., 2012; Matin et al., 2012; Gupta et al., 2015; Spence et al., 2018), testing more "real" applications and examples of technologies (Aday and Yener, 2015; Pennanen et al., 2015; Spence et al., 2018), gaining insights from other members of the supply chain (Pennanen et al., 2015), understanding consumer responses to the use of active and intelligent packaging on specific food groups (Matin et al., 2012; Erdem, 2015; Spence et al., 2018; Zhou and $\mathrm{Hu}, 2018)$, understanding the influence of additional ethical values (Gupta et al., 2015), and the effect of brand on acceptance of novel technology (Henchion et al., 2019) and further understanding of the way smart packing enhances the expected packaging functions.

\section{DATA AVAILABILITY STATEMENT}

The datasets generated for this study are available on request to the corresponding author.

\section{AUTHOR CONTRIBUTIONS}

$\mathrm{MM}$ and $\mathrm{PB}$ contributed conception and design of the project. EY conducted the review, analyzed and provided interpretation of the data, and wrote the first draft of the manuscript. $\mathrm{MM}$ and $\mathrm{PB}$ provided supervision, project administration and funding acquisition, and critical review of manuscript. All authors contributed to manuscript, read and approved the submitted version.

\section{FUNDING}

This article is based on research supported by the New Zealand Ministry of Business Innovation and Enterprise (MBIE, contract number UOOX1712), and the New Zealand Food Safety Science Research Center (NZFSSRC, contract number 33377) and expresses only the views of the authors.

\section{SUPPLEMENTARY MATERIAL}

The Supplementary Material for this article can be found online at: https://www.frontiersin.org/articles/10.3389/fsufs. 2020.00063/full\#supplementary-material

\section{REFERENCES}

Aday, M. S., and Yener, U. (2015). Assessing consumers' adoption of active and intelligent packaging. Br. Food J. 117, 157-177. doi: 10.1108/BFJ-07-2013-0191

Ajzen, I. (1991). The theory of planned behavior. Organ. Behav. Human Dec. Process. 50, 179-211. doi: 10.1016/0749-5978(91)9 0020-T

Alfadul, S., and Elneshwy, A. (2010). Use of nanotechnology in food processing, packaging and safety-review. Afr. J. Food Agric. Nutr. Dev. 10, 2719-2739. doi: 10.4314/ajfand.v10i6.58068

Barska, A., and Wyrwa, J. (2016). "Consumer perception of active and intelligent food packaging," in Problems of Agricultural Economics / Zagadnienia

Ekonomiki Rolnej 252644 [Institute of Agricultural and Food Economics National Research Institute (IAFE-NRI)]

Braun, V., and Clarke, V. (2006). Using thematic analysis in psychology. Qual. Res Psychol. 3, 77-101. doi: 10.1191/1478088706qp063oa

Braun, V., and Clarke, V. (2019). Reflecting on reflexive thematic analysis. Qual. Res. Sport Exerc. Health 11, 589-597. doi: 10.1080/2159676X.2019.1628806

Chen, M.-F. (2008). An integrated research framework to understand consumer attitudes and purchase intentions toward genetically modified foods. Br. Food J. 110, 559-579. doi: 10.1108/00070700810877889

Dagevos, H., and van Ophem, J. (2013). Food consumption value: developing a consumer-centred concept of value in the field of food. Br. Food J. 115, 1473-1486. doi: 10.1108/BFJ-06-2011-0166 
Daoud, M. K., and Trigui, I. T. (2019). "Smart packaging: consumer's perception and diagnostic of traceability information," in 4th International Conference on Digital Economy, ICDEc 2019. Vol. 358. (Springer). 352-370. doi: 10.1007/978-3-030-30874-2_28

Erdem, S. (2015). Consumers' preferences for nanotechnology in food packaging: a discrete choice experiment. J. Agric. Econ. 66, 259-279. doi: 10.1111/1477-9552.12088

Frewer, L., Howard, C., and Shepherd, R. (1995). Consumer perceptions of food risks. Int. J. Food Sci. Technol. 1, 135-146. doi: $10.1111 / j .1365-2621.2005 .01010 . x$

Greehy, G., McCarthy, M., Henchion, M., Dillon, E., and McCarthy, S, (2011). "An exploration of Irish consumer acceptance of nanotechnology applications in food," in Proceedings in Food System Dynamics, 175-198. doi: $10.18461 /$ pfsd.2011.1114

Gupta, N., Fischer, A., and Frewer, L. (2015). Ethics, risk and benefits associated with different applications of nanotechnology: a comparison of expert and consumer perceptions of drivers of societal acceptance. NanoEthics 9, 93-108. doi: 10.1007/s11569-015-0222-5

Henchion, M., McCarthy, M., Dillon, E., Greehy, G., and McCarthy, S. (2019). Big issues for a small technology: Consumer trade-offs in acceptance of nanotechnology in food. Innov. Food Sci. Emerg. 58:102210. doi: 10.1016/j.ifset.2019.102210

Katare, B., Yue, C., and Hurley, T. (2016). "Consumer willingness to pay for nano-packaged food products: evidence from eye-tracking technology and experimental auctions," in Food Markets: Consumer Perceptions, Government Regulations and Health Impacts (New York, NY: Nova Science Publishers, Inc), 55-84.

Köster, E. P. (2009). Diversity in the determinants of food choice: a psychological perspective. Food Qual. Pref. 20, 70-82. doi: 10.1016/j.foodqual.2007.11.002

Kushwah, S., Dhir, A., Sagar, M., and Gupta, B. (2019). Determinants of organic food consumption. A systematic literature review on motives and barriers. Appetite 143:104402. doi: 10.1016/j.appet.2019.104402

Lindqvist, U., Federley, M., Hakola, L., Laukkanen, M., Mensonen, A., and Viljakainen, A. (2012). Consumer demand for information accessible through automatic identification. Pack. Technol. Sci. 25, 1-6. doi: 10.1002/pts.951

López-Vázquez, E., Brunner, T. A., and Siegrist, M. (2012). Perceived risks and benefits of nanotechnology applied to the food and packaging sector in México. Br. Food J. 114, 197-205. doi: 10.1108/00070701211202386

Loučanová, E., Kalamárová, M., and Parobek, J. (2017). The innovative approaches to packaging-comparison analysis of intelligent and active packaging perceptions in Slovakia. Studia Universitatis Vasile Goldis AradEconomics Series 27, 33-44. doi: 10.1515/sues-2017-0007

Loučanová, E., Kalamárová, M., Parobek, J., and Dopico, A. (2016). Simulation of intelligent and active packaging perceptions in slovakia. Acta Simulatio Int. Sci. J. Simulation 2, 13-17.

Loučanová, E., Nosálová, M., and Olšiaková, M. (2019a). The development of the innovation status and impact of smart packaging on Slovak consumers. Acta Logistica 6, 115-122. doi: 10.22306/al.v6i4.137

Loučanová, E., Nosálová, M., Parobek, J., and Dopico, A. (2018). The Kano model use to evaluate the perception of intelligent and active packaging of slovak customers. Studia Universitatis "Vasile Goldis" Arad-Economics Series 28, 35-45. doi: 10.2478/sues-2018-0003

Loučanová, E., Parobek, J., Nosálová, M., and Dopico, A. (2019b). The Perception of Respondents of Intelligent Packaging in Slovakia as Ecological Innovations. Studia Universitatis "Vasile Goldis" Arad-Economics Series 29, 58-67. doi: 10.2478/sues-2019-0004

Matin, A. H., Goddard, E., Vandermoere, F., Blanchemanche, S., Bieberstein, A., Marette, S., et al. (2012). Do environmental attitudes and food technology neophobia affect perceptions of the benefits of nanotechnology? Int. J. Consum. Stud. 36, 149-157. doi: 10.1111/j.1470-6431.2011.01090.x

Moher, D., Liberati, A., Tetzlaff, J., and Altman, D. G. (2009). Preferred reporting items for systematic reviews and meta-analyses: the PRISMA statement. Ann. Internal Med. 151, 264-269. doi: 10.7326/0003-4819-151-4-2009081 80-00135

Nosálová, M., Loučanová, E., and Parobek, J. (2018). Perception of packaging functions and the interest in intelligent and active packaging. Prob. Agric. Econ. 4, 141-152. doi: $10.30858 /$ zer/100715
O'Callaghan, K. A. M., and Kerry, J. P. (2016). Consumer attitudes towards the application of smart packaging technologies to cheese products. Food Pack. Shelf Life 9, 1-9. doi: 10.1016/j.fpsl.2016.05.001

Öner, M. A., Karaca, F., Beşer, S. G., and Yildirmaz, H. (2013). Comparison of nanotechnology acceptance in Turkey and Switzerland. Int. J. Innov. Technol. Manag. 10, 1-21. doi: 10.1142/S0219877013400075

Pennanen, K., Focas, C., Kumpusalo-Sanna, V., Keskitalo-Vuokko, K., Matullat, I., Ellouze, M., et al. (2015). European consumers' perceptions of time-temperature indicators in food packaging. Packag. Technol. Sci. 28, 303-323. doi: 10.1002/pts.2105

Poole, C. P. Jr., and Owens, F. J. (2003). Introduction to Nanotechnology. Hoboken, NJ: John Wiley \& Sons.

Ram, S., and Sheth, J. N. (1989). Consumer resistance to innovations: the marketing problem and its solutions. J. Consum. Market. 6, 5-14. doi: 10.1108/EUM0000000002542

Robertson, G. L. (2013). Food Packaging: Principles and Practice, 3 Edn. Boca Raton, FL: CRC Press, Taylor \& Francis Group, LLC.

Rogers, E. M. (2010). Diffusion of Innovations. New York, NY: Simon and Schuster. Satter, E. (2007). Hierarchy of food needs. J. Nutr. Educ. Behav. 39, S187-S188. doi: 10.1016/j.jneb.2007.01.003

Schnettler, B., Crisóstomo, G., Mora, M., Lobos, G., Miranda, H., and Grunert, K. G. (2014). Acceptance of nanotechnology applications and satisfaction with food-related life in southern Chile. Food Sci. Technol. 34, 157-163. doi: 10.1590/S0101-20612014005000001

Sheth, J. N., Newman, B. I., and Gross, B. L. (1991). Why we buy what we buy: a theory of consumption values. J. Bus. Res. 22, 159-170. doi: 10.1016/0148-2963(91)90050-8

Siegrist, M., Cousin, M. E., Kastenholz, H., and Wiek, A. (2007). Public acceptance of nanotechnology foods and food packaging: the influence of affect and trust. Appetite 49, 459-466. doi: 10.1016/j.appet.2007.03.002

Sodano, V., Gorgitano, M. T., Verneau, F., and Vitale, C. D. (2016). Consumer acceptance of food nanotechnology in Italy. Br. Food J. 118, 714-733. doi: 10.1108/BFJ-06-2015-0226

Spence, M., Stancu, V., Elliott, C. T., and Dean, M. (2018). Exploring consumer purchase intentions towards traceable minced beef and beef steak using the theory of planned behavior. Food Control 91, 138-147. doi: 10.1016/j.foodcont.2018.03.035

Stampfli, N., Siegrist, M., and Kastenholz, H. (2010). Acceptance of nanotechnology in food and food packaging: a path model analysis. $J$. Risk Res. 13, 353-365. doi: 10.1080/13669870903233303

Van Wezemael, L., Ueland, O., and Verbeke, W. (2011). European consumer response to packaging technologies for improved beef safety. Meat Sci. 89, 45-51. doi: 10.1016/j.meatsci.2011.03.019

Vandermoere, F., Blanchemanche, S., Bieberstein, A., Marette, S., and Roosen, J. (2011). The public understanding of nanotechnology in the food domain: the hidden role of views on science, technology, and nature. Public Understand. Sci. 20, 195-206. doi: 10.1177/0963662509350139

Wilson, C. T., Harte, J., and Almenar, E. (2018). Effects of sachet presence on consumer product perception and active packaging acceptability - A study of fresh-cut cantaloupe. $L W T$ 92, 531-539. doi: 10.1016/j.lwt.2018.02.060

Yam, K. L., and Lee, D. S. (2012). Emerging Food Packaging Technologies: Principles and Practice. Philadelphia, PA: Elsevier. doi: 10.1533/9780857095664

Zhou, G., and Hu, W. (2018). Public acceptance of and willingnessto-pay for nanofoods in the U.S. Food Control, 89, 219-226. doi: 10.1016/j.foodcont.2018.02.004

Conflict of Interest: The authors declare that the research was conducted in the absence of any commercial or financial relationships that could be construed as a potential conflict of interest.

Copyright (c) 2020 Young, Mirosa and Bremer. This is an open-access article distributed under the terms of the Creative Commons Attribution License (CC BY). The use, distribution or reproduction in other forums is permitted, provided the original author(s) and the copyright owner(s) are credited and that the original publication in this journal is cited, in accordance with accepted academic practice. No use, distribution or reproduction is permitted which does not comply with these terms. 